\title{
On beach cusp formation
}

\author{
NICHOLAS DODD ${ }^{1}$, ADAM M. STOKER ${ }^{1}$, \\ DANIEL CALVETE ${ }^{2}$ AND ANURAK SRIARIYA WA T \\ ${ }^{1}$ School of Civil Engineering, University of Nottingham, Nottingham, NG7 2RD, UK \\ ${ }^{2}$ Dept. de Fisica Aplicada, Univeristat Politecnica de Catalunya, Barcelona, Spain
}

(Received 29 September 2005 and in revised form 6 October 2007)

A system of shallow water equations and a bed evolution equation are used to examine the evolution of perturbations on an erodible, initially plane beach subject to normal wave incidence. Both a permeable (under Darcy's law) and an impermeable beach are considered. It is found that alongshore-periodic morphological features reminiscent of swash beach cusps form after a number of incident wave periods on both beaches. On the permeable (impermeable) beach these patterns are accretional (erosional). In both cases flow is 'horn divergent'. Spacings of the cusps are consistent with observations, and are close to those provided by a standing synchronous linear edge wave. An analysis of the processes leading to bed change is presented. Two physical mechanisms are identified: concentration gradient and flow divergence, which are dominant in the lower and upper swash respectively, and their difference over a wave cycle leads to erosion or deposition on an impermeable beach. Infiltration enters this balance in the upper swash. A bed wave of elevation is shown to advance up the beach at the tip of the uprush, with a smaller wave of depression on the backwash. It is found that cusp horns can grow by a positive feedback mechanism stemming from decreased (increased) backwash on positive (negative) bed perturbations.

\section{Introduction}

Beach cusps are regularly spaced crescentic morphological patterns formed in the swash zone of a beach. They consist of seaward-pointing horns with steep lateral slopes separated by a gentler sloping embayment (see e.g. Coco, O'Hare \& Huntley 1999). Typically, they have spacings $\lambda_{c}$ (i.e. horn-to-horn distances) of between 1 and $50 \mathrm{~m}$ (Masselink \& Pattiaratchi 1998). Hereafter we refer to them as swash cusps, to differentiate them from other shoreline periodic features such as giant cusps (Inman \& Guza 1982), which have larger spacings $\left(\lambda_{c}>75 \mathrm{~m}\right)$ and which are believed to form as part of larger surf-zone circulation cells (Inman \& Guza 1982; Calvete et al. 2005). Swash cusps are thought to shape the beach by either erosion of the existing beach profile (Sallenger 1979; Guza \& Bowen 1981), or deposition at the shoreline (Masselink \& Pattiaratchi 1998).

There is general agreement about the conditions associated with cusp generation. Although a few field observations cite horn-convergent flows (e.g. Dyer 1986) swash cusps are now thought to be developed and maintained by a significantly twodimensional horn-divergent swash flow circulation pattern (see figure 1 in Masselink \& Pattiaratchi 1998). (Note that 'horn-divergent' here means that the flow splits to either side of the horn in the uprush and not that the flow is divergent on the uprush.) Swash cusps are usually associated with reflective wave conditions, relatively steep beach 
gradients, and normally incident waves, which can either be plunging or surging. It has also been noted that they occur on coarser grained beaches (see Coco et al. 1999, for a comprehensive overview).

Historically, there have been differing views on the mechanisms leading to the development of swash cusps (see Coco et al. 1999). Two theories have achieved some success in describing the formation and behaviour of beach cusps: the standing edge wave model (see Guza \& Inman 1975); and the self-organization model (see Werner \& Fink 1993; Coco, Huntley \& O’Hare 2000).

In the first, an alongshore standing subharmonic edge wave superimposed on a normally incident reflected wave produces a systematic alongshore variation in swash height, which results in a regular erosional perturbation, leading to the cuspate pattern (Guza \& Inman 1975) of spacing $\lambda_{c}=\lambda_{\text {sub }} / 2$, where $\lambda_{\text {sub }}$ is the edge wavelength. The formation of the cusps, however, reduces the standing wave amplitude (Guza \& Inman 1975; Guza \& Bowen 1981), so the process is self-limiting. Further, fully reflective wave conditions are required, which limits the applicability of this mechanism. It is now thought that such a model may explain the initiation of cusp formation, but that a different, positive feedback is needed to maintain the cuspate pattern. This is supported by the fact that subharmonic edge waves with their characteristic runup at alternate cusps are not often seen on real beaches (Inman \& Guza 1982).

Self-organizational modelling is based on a set of abstracted rules for sediment movement. It has proven successful in reproducing cusp-like features and their evolution. In the approach (see Werner \& Fink 1993; Coco et al. 2000, 2003) flow is represented as discrete volumes (particles) with an associated velocity and sediment carrying capacity (related to the velocity). Water particle motion is described using ballistic theory on a slope, and the sediment transport flux is a cubic relationship with local particle velocity. Particles of water deposit (erode) sediment as they decelerate (accelerate). Individual changes in local cellular beach level are then smoothed so as to distribute them to cells without water, the smoothing principle being to minimize the local variation to a plane (see Coco et al. 2000). These models predict that

$$
\lambda_{c}=f S_{e}
$$

where $S_{e}$ is the horizontal swash excursion (the horizontal distance between the limits of runup and rundown; see Komar \& Holman 1986) and $f$ is a constant in the range 1-3 (Werner \& Fink 1993); Coco et al. (1999) found the average value of $f$ to be 1.63 .

The field evidence is mixed: Masselink et al. (2004) found no evidence for the existence of edge waves in a cusp field; on the other hand Ciriano et al. (2005) do record edge wave activity. Neither approach has therefore proved satisfactory, either because of purely linear dynamics and limited success, or because of a somewhat ad hoc approach based on limited physics.

Here we investigate a fully coupled morpho-hydrodynamical system based on flow equations (nonlinear shallow water equations) and a sediment conservation equation. We also include the effects of beach permeability through Darcy's law. This achieves two ends, namely, the inclusion of physics that is important on coarser grained beaches on which cusps predominantly occur, and a mechanism for phase-averaged onshore sediment transport, which is necessary if purely offshore movement that accompanies power-law-based sediment transport laws is to be avoided (see Pritchard \& Hogg 2005).

In contrast to previous approaches, therefore, we consider a consistent set of nonlinear equations in which bed and flow interact without constraint, other than 


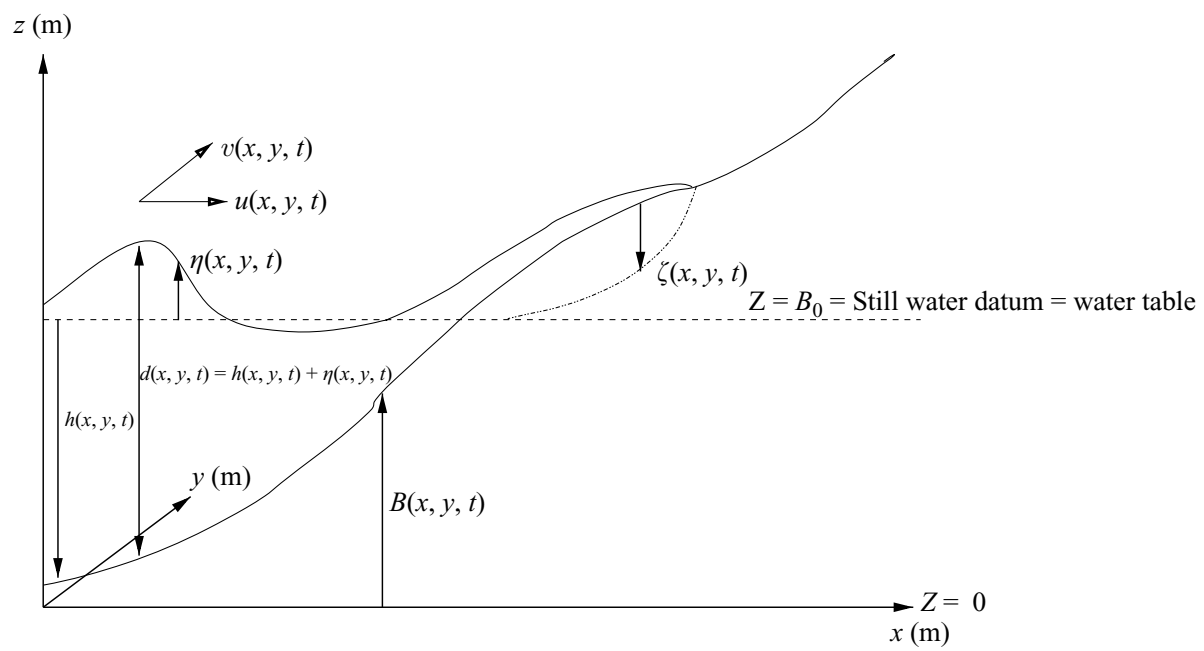

FIGURE 1. The coordinate system and physical situation.

that implied by shallow water dynamics and the sediment transport relation. The aim is to investigate if cusps can indeed form and to understand the process by which they do so.

In the next section we present the equations and parameterizations, followed by the numerical model and the numerical experiments.

\section{Formulation}

We consider an initially rectilinear coast, with $y(x)$ the alongshore (cross-shore) coordinate, and $z$ the vertical coordinate $\left(z=B_{0}\right.$ is the still water level). The beach surface (dry or submerged) is given by $z=B(x, y, t)$ : see figure 1 . Morphological evolution is described by a sediment continuity equation

$$
B_{, t}+\xi q_{1, x}+\xi q_{2, y}=0
$$

where $\boldsymbol{q}$ is the volumetric horizontal sediment flux vector, $\boldsymbol{x}=\left(x_{1}, x_{2}\right) \equiv(x, y), t$ is time and $\xi=1 /(1-n)$ where $n$ is porosity of the sand. We thus neglect effects due to rapid changes in suspended sediment concentration. Water motions are described by shallow water equations, including the effects of infiltration into the beach:

$$
\begin{aligned}
d_{, t}+(d u)_{, x}+(d v)_{, y} & =-w, \\
(d u)_{, t}+\left(d u^{2}+\frac{g d^{2}}{2}\right)_{, x}+(d u v)_{, y} & =-g d B_{, x}-\frac{f_{w}}{2}|\boldsymbol{u}| u-u w, \\
(d v)_{, t}+(d u v)_{, x}+\left(d v^{2}+\frac{g d^{2}}{2}\right)_{, y} & =-g d B_{, y}-\frac{f_{w}}{2}|\boldsymbol{u}| v-v w,
\end{aligned}
$$

where $d$ is the total water depth, $\boldsymbol{u}=(u, v)$ is the depth-averaged velocity (from $B$ to free-surface elevation $\eta$ ), and $f_{w}$ is a dimensionless bed friction factor. The term $w$ is the infiltration velocity of water percolating into the beach under a head of water. The free-slip bed boundary conditions applied are

$$
B_{, t}+u_{j} B_{, x_{j}}-W=w
$$


where $W$ is the vertical velocity in the free region at the bed, and these state that the only normal component to the bed is the infiltration velocity and that this is vertical. The approach taken here is based on that of Packwood (1983), apart from (2.5) and terms involving $w$ in (2.3) and (2..4), and is consistent with the assumption of Darcy flow within the beach. Note that the form of the equations is such that infiltration has no effect on the momentum budget other than through the loss of water.

Following Packwood (1983) $w$ is determined from the equation

$$
w=n \zeta_{, t}=K\left(1+\frac{d}{\zeta}\right)
$$

based on Darcy's law (see Dicker 1969; Chow, Maidment \& Mays 1988), where $K$ is the hydraulic conductivity of the sediment (taken here to be $0.01 \mathrm{~m} \mathrm{~s}^{-1}$, consistent with coarse sand; see Packwood \& Peregrine 1980), and $\zeta$ the depth of infiltration in a single swash event (see figure 1). Thus, the infiltration front is initially driven by a hydrostatic pressure head $d$, and descends also under its own weight. Here we only calculate the infiltration front under each swash event. After the wave has retreated we discard the infiltration 'wedge' or 'lens'. There is therefore no groundwater modelling, no exfiltration, and no suction head; water is therefore not conserved: see Appendix A for details of this approach.

The sediment flux $\boldsymbol{q}$ is specified as

$$
\boldsymbol{q}=A\left(u|\boldsymbol{u}|^{2}, v|\boldsymbol{u}|^{2}\right)
$$

where $A$ is a dimensional constant $\left[T^{2} / L\right]$ related to the beach material and flow regime. The choice of (2.7) is motivated by numerical considerations (see Hudson \& Sweby 2003); to retain consistency with Coco et al. (2000), who used the same relation; and because the relation is a reasonable empirical swash sediment transport relation (see e.g. Masselink \& Li 2001; Butt et al. 2004; Hsu \& Raubenheimer 2006). Here we treat the formula as a total-load formula. The constant $A$ can be approximated using the sediment transport equation of Van Rijn to yield an expression giving $A$ as a function of median grain diameter $\left(d_{50}\right)$ or it can be calibrated using experimental data (see Hudson \& Sweby 2003). Here we do the latter and take $A=0.004 \mathrm{~s}^{2} \mathrm{~m}^{-1}$.

The relation (2.7) is modified by the inclusion of a downslope term:

$$
\boldsymbol{q}^{*}=\boldsymbol{q}-\frac{1}{\tan \phi}|\boldsymbol{q}| \nabla b .
$$

This allows sediment to move downslope under gravity as long as it is already in motion; $b$ is a bed perturbation from the initial bathymetry $(B(x, y, t=0))$; $\phi$ is the angle of repose of the sediment, here $32^{\circ}$.

\subsection{Numerical method}

The numerical scheme is effected on a Cartesian grid with the $x$-coordinate running onshore and $y$ alongshore. Solution variables are stored at cell centres $\left(\boldsymbol{x}_{i j}=((i-\right.$ $1 / 2) \Delta x,(j-1 / 2) \Delta y)=\left(x_{i}, y_{j}\right)$ for $i=1, \ldots, N_{x}, j=1, \ldots, N_{y}$, where $N_{x} \Delta x=L_{x}$ and $N_{y} \Delta y=L_{y}$ ) in a finite volume approach, and a wet-dry boundary is defined based on a minimum wet cell depth: $d_{\min }$ (here $2 \mathrm{~mm}$ ) and a secondary threshold below which the water is no longer dynamically active in the model (here $2 \mathrm{~cm}$ ). See Hubbard \& Dodd (2002) for more details of the layout and wetting and drying approach, which is used for the bed level $B$ as well. Numerical solution is effected by means of the Roe-type scheme of Hudson \& Sweby (2003), and a Minmod flux limiter is used. Solution of the four-equation system is simultaneous, so no iteration to a steady state 
or morphodynamical time-stepping is necessary (or desirable). Other derivatives in (2.1)-(2.4) are treated in a pointwise fashion (i.e. by central differencing).

Offshore boundary conditions for the flow are characteristics based, thus allowing reflected waves to exit the domain. This is achieved by priming the two layers of dummy cells that surround the domain with the incoming signal $\left(d_{i n c}, u_{i n c}\right)$, and then allowing the approximate Riemann solver to achieve the characteristic decomposition. The bed levels in the dummy cells at the offshore boundary are copied from those in $B_{1, j}$, so that the bed level is not forced there. Three types of lateral boundary condition were tested: reflective

$$
(d, u, B)_{i, 0 /-1 / N_{y}+1 / N_{y}+2}=(d, u, B)_{i, 1 / 2 / N_{y} / N_{y}-1} ; v_{i, 0 /-1 / N_{y}+1 / N_{y}+2}=-v_{i, 1 / 2 / N_{y} / N_{y}-1}
$$

extrapolative

and periodic

$$
(d, u, v, B)_{i, 0 /-1 / N_{y}+1 / N_{y}+2}=(d, u, v, B)_{i, 1 / N_{y}}
$$

$$
(d, u, v, B)_{i, 0 /-1 / N_{y}+1 / N_{y}+2}=(d, u, v, B)_{i, N_{y} / N_{y}-1 / 1 / 2} .
$$

In all numerial simulations no difference in $\lambda_{c}$ was observed between the approaches. Adjacent to the lateral boundaries, the first two approaches sometimes resulted in an eventual local breakdown in the numerical solution. We therefore use periodic boundary conditions throughout, with $L_{y} \geqslant 6 \lambda_{c}\left(4 \lambda_{c}\right.$ was found to be large enough to ensure no suppression of naturally occurring wavelengths for which $L_{y} \neq n \lambda_{c}$ for $n$ a natural number).

\subsubsection{Infiltration}

After both bed and flow have been updated at each time level, (2.6) is solved to determine the infiltration velocity $w$. This is done, following Packwood (1983), by calculating the infiltration depth $\zeta$ of the water due to a pressure head $d$. This equation is only solved at any cell location $\boldsymbol{x}_{i j}$ when $B>B_{0}$ (i.e. the beach is above the still water level), and the calculation begins when the free flow region above cell $\boldsymbol{x}_{i j}$ is wetted. Then we follow Packwood (1983) (see also Karambas 2003) and assume a linear variation between $d\left(\boldsymbol{x}_{i j}, t_{n}\right)$ and $d\left(\boldsymbol{x}_{i j}, t_{n}+\Delta t\right)$ during the initial integration from zero to finite $\zeta$. In subsequent time-steps we use a fourth-order Runge-Kutta scheme. Note that in theory $d\left(\boldsymbol{x}_{i j}, t_{n}\right)$ decreases as $\zeta$, measured from the beach face at $\boldsymbol{x}_{i j}$, increases. We do not correct $d$ to compensate for the change in head during this integration; rather we calculate $w$ at the new time via (2.6) and then extract water (2.2) and momentum (2.3)-(2.4) based on the calculated $w$ and the new time level prior to the next solution step using the Roe-type scheme.

\section{Numerical simulations}

Simulations are performed on an initially plane, alongshore-uniform sloping beach with a slope $\tan \beta=0.14$, which is the same as that used by Coco et al. (2000), and still water depth of $1 \mathrm{~m}$ at the offshore boundary $\left(x=x_{0}\right)$. The chosen beach slope is representative of steep slopes in the swash region of permeable beaches. The incoming signal is a sine wave (height $H_{0}$, period $T$ ) to which a random perturbation $\epsilon$ is added at each alongshore cell so that $\eta\left(y_{j}, t\right)=\eta_{0}(t)+\epsilon\left(y_{j}, t\right) ; \epsilon$ is randomly chosen from a uniform normal distribution on interval $\left[-\eta_{\epsilon}, \eta_{\epsilon}\right]$. Here we use $\eta_{\epsilon}=2 \mathrm{~cm}$. These values are subsequently smoothed in space and time in order to remove high-frequency variation before being applied. This is done with a 5-point weighted average in space and a simple average in time between the new perturbation and the previously 
$T$

$[\mathrm{s}]$

3

4

5

6

7

8
Permeable

\begin{tabular}{c}
\hline Linear growth \\
{$\left[\mathrm{s}^{-1}\right]$} \\
0.057 \\
0.064 \\
0.048 \\
0.025 \\
0.017 \\
$(0.0064)$
\end{tabular}

$[\mathrm{m}]$

$4.2 \quad 3.1$

$\begin{array}{ll}5.3 & 2.7\end{array}$

$8.3 \quad 3.4$

$10.0 \quad 3.4$

$12.5 \quad 3.7$

(13.8) (3.6)
Impermeable

\begin{tabular}{ccc}
\hline Linear growth rate & $\lambda_{c}$ & $f$ \\
{$\left[\mathrm{~s}^{-1}\right]$} & {$[\mathrm{m}]$} & \\
0.041 & 2.9 & 2.0 \\
0.027 & 4.4 & 2.0 \\
0.021 & 6.3 & 2.2 \\
$(0.010)$ & $(8.9)$ & $(2.9)$
\end{tabular}

TABLE 1. Summary of the results of the morphodynamical simulations. Note that the linear growth rates were calculated by Fourier analysis of alongshore sections at both cusp (horn and embayment) and trough (anti-phase pool and shelf) locations. Estimates were in agreement at both locations except for $T=3 \mathrm{~s}$ (permeable), where there was a $20 \%$ variation. The figure shown is the average. NB. Figures in parentheses denote only weak evidence for cusps.

applied perturbation. The sensitivity of the simulations to both $\eta_{\epsilon}$ and smoothing was examined; larger (smaller) values of $\eta_{\epsilon}$ lead to faster (smaller) growth of beach forms but no qualitative change. Variation in smoothing has no significant effect. Cell sizes are $\Delta x=\Delta y=0.1 \mathrm{~m}$, for which convergence is achieved.

In the simulations we use a (default) period $T=5 \mathrm{~s}$ and height $H_{0}=0.25 \mathrm{~m}$. These are representative of those observed in the field when beach cusps have formed (see Coco et al. 1999, table 1), and correspond to $\tan \beta / \sqrt{H_{0} / L_{\infty}} \approx 1.75$, implying that the waves are marginally within the plunging breaker regime (see Mei 1990). These conditions are also similar to those of Coco et al. (2000), who also observed cusp formation in their model. A constant bed friction coefficient $f_{w}=0.05$ is used.

\subsection{Beach cusps on permeable and non-permeable beaches}

Figure 2 shows the change in the bed level relative to the plane beach over $500 \mathrm{~s}$ (100 periods). After 20 periods a rhythmic morphological pattern and flow field has emerged. This pattern continues to develop into that of beach cusps, with horns (here at 15, 23.5 and $32 \mathrm{~m}$ ) and embayments (11, 19.5 and 28 ), giving $\lambda_{c} \approx 8.3 \mathrm{~m}$, $\Rightarrow f \approx 3.4$, Note the clear horn-divergent phase-averaged flow. The cusp pattern is primarily depositional in the upper swash, but erosional further offshore. After $500 \mathrm{~s}$ a series of shoals and pools opposite (respectively) the embayments and the horns are developing. These are also observed in the field.

Figure 3 shows the equivalent bed changes over $500 \mathrm{~s}$ on a non-permeable beach. The phase-averaged flow is initially offshore directed, but, after 80 periods, we find the horn-divergent flow associated with cusps $(f \approx 2.2)$. These cusps are erosive, however, and their upper limit recesses. The cusps also develop more slowly.

Further simulations were run for both permeable and impermeable beaches. The results are summarized in table 1.

\section{Physical mechanisms}

To understand the mechanisms for changes in the bed it is instructive to combine (2.2) and (2.1):

$$
B_{, t}\left(1+\xi \frac{\alpha}{d}\right)=-\xi d \boldsymbol{u} \cdot \nabla \frac{\alpha}{d}+\xi \frac{\alpha}{d}\left(\eta_{, t}+w\right)+\xi \nabla \cdot\left(\frac{\alpha}{\tan \phi}|\boldsymbol{u}| \nabla b\right)
$$



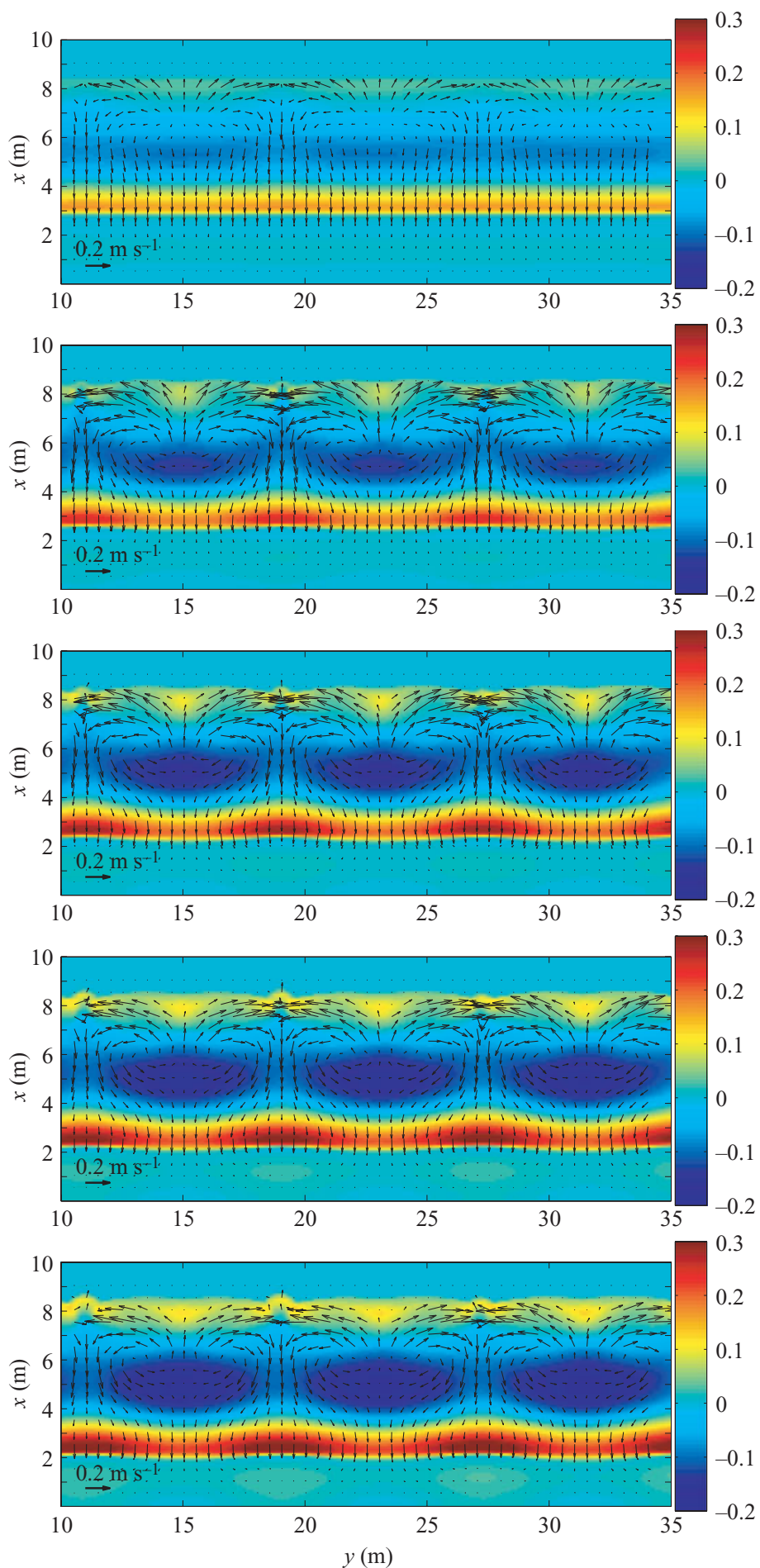

Figure 2. Change in bed level $(\mathrm{m})$ relative to a plane beach (colours) after 20, 40, 60, 80 and 100 periods, on permeable beach, and velocity vectors averaged over preceeding period. Only the central $25 \mathrm{~m}$ of the domain are shown. 

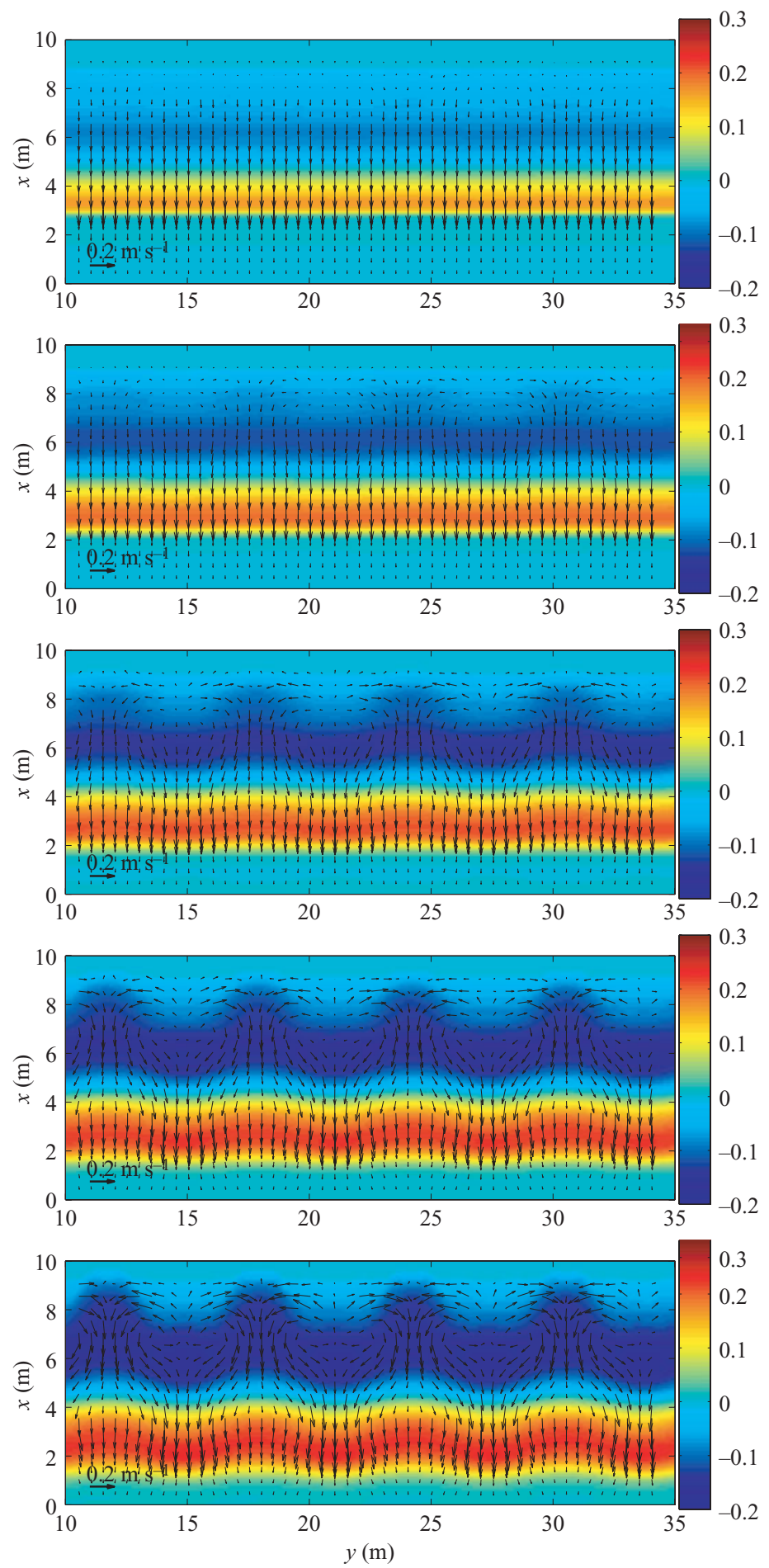

FIGURE 3. Change in bed level (m) on impermeable beach. For other details see figure 2. 
where $\alpha=A|\boldsymbol{u}|^{2}$. Thus, $\alpha / d$ represents a depth-averaged concentration, which we denote $C(\geqslant 0)$. The left of (4.1) is (essentially) the rate of bed change. The first two terms on the right result from the assumption $\boldsymbol{q}=\alpha \boldsymbol{u}$, namely, that the sediment ( $\alpha$ is interpreted as the total volume of sediment in motion per unit area) is advected by the flow. This concentration may be supposed to be located mostly near the bed. The term $-\xi d \boldsymbol{u} \cdot \nabla(\alpha / d)$ is best understood by considering a steady flow with spatially varying concentration; in a swash context this could be a steady hydraulic jump in the backwash. Thus high concentrations in the supercritical flow moving into the jump and lower concentrations behind the jump provide an implied positive gradient in $C$ with a negative $u$ ( $x$ positive onshore). Thus deposition will occur as the flow decelerates through the jump. (NB Turbulence within the jump, which can lead to local scour, is not included in this term, or in the shallow water equations.) This term is analogous to that of Falqués, Coco \& Huntley (2000), who examined phase-averaged equations and bed growth in the surf zone. In their analysis high concentrations are caused by wave-induced stirring, whereas here the flow and depth-averaged concentration are more intimately linked.

The other part of the sediment flux divergence, $(\alpha / d) \eta_{, t}$, results from the flow divergence, and, similarly, is most easily understood by neglecting the concentration gradient. Thus, for a locally spatially uniform $C$ flow convergence (divergence) leads to deposition (erosion). In the swash region we expect flow convergence in the uprush and divergence in the backwash. In Appendix $\mathrm{C}$ we illustrate these two effects, which are usually in opposition to each other, using the analytical solution of Shen \& Meyer (1963).

It can be seen that $\xi(\alpha / d) w \geqslant 0$, so infiltration is purely depositional. Note also that for periodic flow on an immobile bed with infiltration, $\bar{\nabla} d \boldsymbol{u}=-\bar{w}$, which implies convergent flow, where an overbar denotes a period (phase) average. For an erodible bed subject to periodic forcing we may therefore expect $\overline{\nabla d u} \approx-\bar{w}$. The final term represents bed diffusion.

\subsection{Cross-shore dynamics}

It is useful to examine pure cross-shore dynamics under equivalent conditions. Accordingly, we ran a series of one-dimensional experiments on an otherwise identical initial beach. The results for the permeable beach are shown in figure 4 . The growth of the swash bar and the breaker bar are consistent with the behaviour shown in figure 2. A cross-shore equilibrium profile develops after about $7000 \mathrm{~s}$.

A similar experiment on the impermeable beach was performed: see figure 5. The profile is clearly erosive, consistent with figure 3 . In figure $4 S_{e}$ reduces from $2.8 \mathrm{~m}$, its value after 5 periods (when initial transients have left the domain), to $2.7 \mathrm{~m}$ after 80 periods. The reflection coefficient for the equilibrium profile is $|R|=0.75\left(S_{e}=2.2 \mathrm{~m}\right)$.

To look at the role of the terms in (4.1) we focus on cross-shore profiles in figure 4 and figure 5 after $250 \mathrm{~s}$. Over one cycle the divergence term is directly opposed to the concentration gradient term in the swash region (figure 6) (see also Appendix C), with the permeability making the difference between an erosive and a depositional beach. This effect also goes beyond just the region where the permeability operates, because less water is available to erode in the backwash.

In figure 7 we can see $C$, and the flow and sediment flux divergence (excluding diffusion), over a wave cycle. It can be seen that during the uprush a bed wave of elevation (deposition) is driven up the beach $\left(B_{, t}=-\xi \nabla q\right.$ neglecting diffusion), at the speed of the incoming wave, caused by the flow convergence. In its lee the positive 

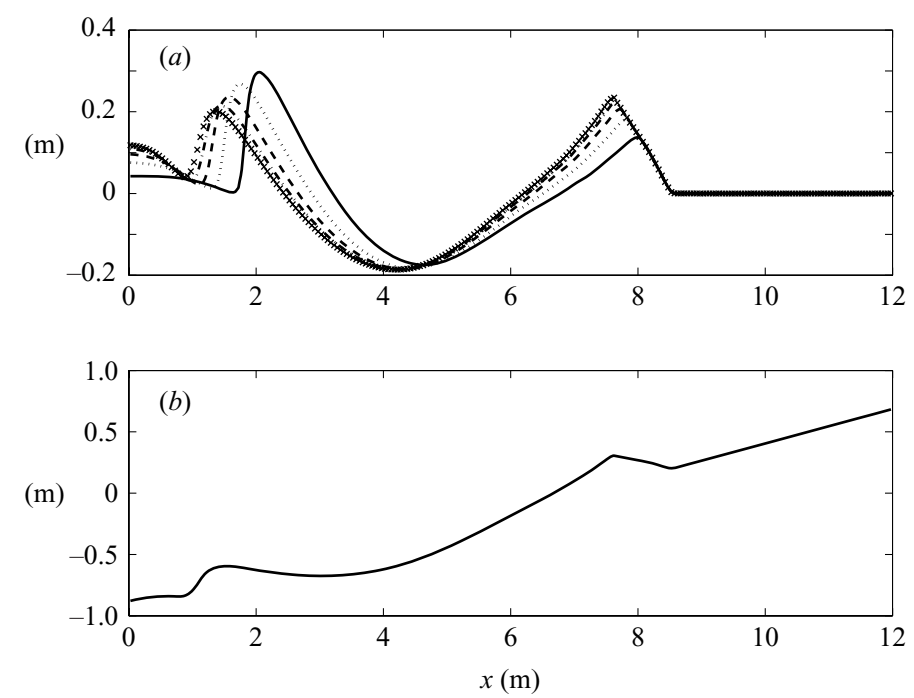

FIGURE 4. Permeable beach. Cross-shore experiment. (a) Change in bed level (m) relative to a plane beach over $5000 \mathrm{~s}$ (1000 periods). Solid line: $1000 \mathrm{~s}$; dotted line: 2000 s; Dashed line: $3000 \mathrm{~s}$; dot-dashed line: $4000 \mathrm{~s}$; $\times$ : $5000 \mathrm{~s}$. (b) Final beach profile after $5000 \mathrm{~s}$.
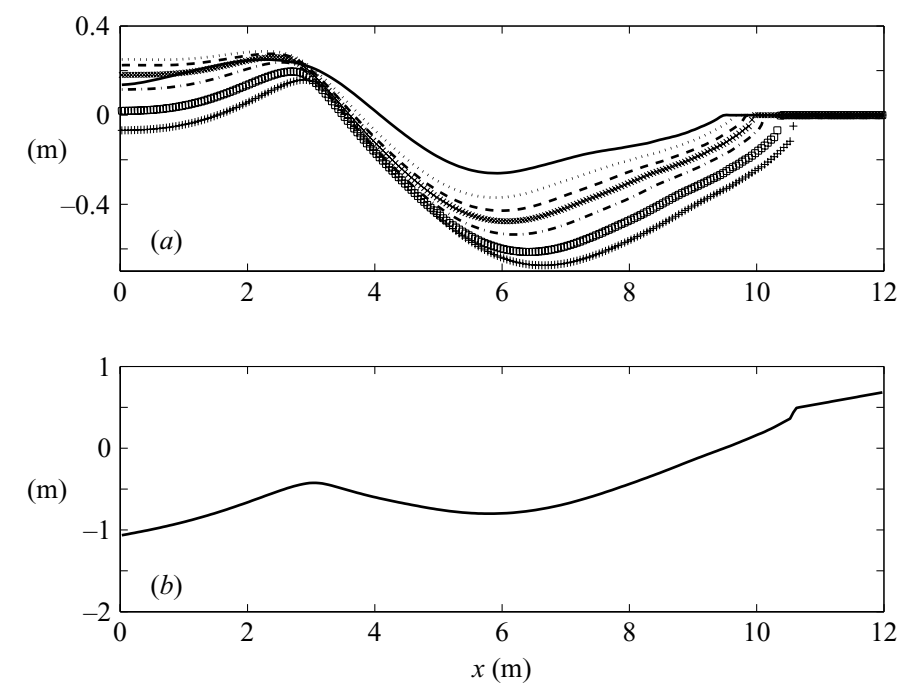

Figure 5. Impermeable beach. Cross-shore experiment. (a) Change in bed level (m) relative to a plane beach over $20000 \mathrm{~s}$ (4000 periods). Solid line: $1000 \mathrm{~s}$; dotted line: $3000 \mathrm{~s}$; dashed line: $5000 \mathrm{~s} ; \times: 7000 \mathrm{~s}$; dot-dashed line: $10000 \mathrm{~s} ; \square: 15000 \mathrm{~s} ;+: 20000 \mathrm{~s}$. $(b)$ Final beach profile after $20000 \mathrm{~s}$.

concentration gradient then causes erosion. Note that this is analagous to the erodiblebed dambreak case shown in Appendix B, figure 17. As the water recedes a similar wave follows the backwash. This highly dynamic sediment behaviour occurs because of the high Froude numbers in this region, and is also the reason why decoupling morphodynamic and hydrodynamic time scales in the swash is not appropriate (see 

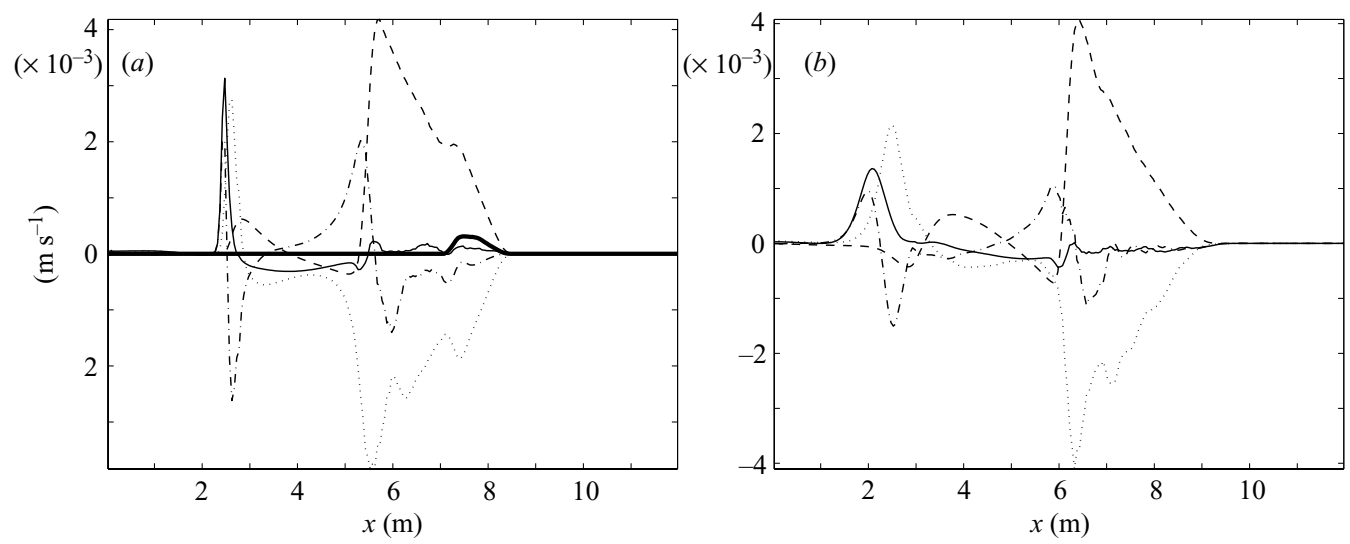

FiguRE 6. Phase-averaged terms in (4.1) for $(a)$ permeable beach and $(b)$ impermeable beach, cross-shore experiment from $276-281 \mathrm{~s}$. Solid line: $b_{, t}$; dashed line: $\xi\left(\overline{\alpha / d) \eta} \eta_{, t}\right.$; dotted line: $-\xi \overline{d \boldsymbol{u} \cdot \nabla(\alpha / d)}$; dot-dash line: $\xi \overline{\nabla \cdot((\alpha / \tan \phi)|\boldsymbol{u}| \nabla b)}$; thick solid line: $\xi \overline{(\alpha / d) w}$.

Hudson et al. 2005). By rewriting (4.1) in the absence of bed diffusion as

$$
B_{, t}+\frac{\xi C}{1+\xi C} \boldsymbol{u} \cdot \nabla b=\frac{C \xi}{1+\xi C}\left(\eta_{, t}+\boldsymbol{u} \cdot \nabla \eta-\boldsymbol{u} \cdot \nabla \alpha\right)
$$

it can be seen that the bed wave is forced by the flow (as is expected; bed diffusion through the angle of repose is the only restoring mechanism of the sediment), and that as $C \rightarrow \infty$ (as $d \rightarrow 0$ or $u \rightarrow \infty$ ) this forcing happens on the time scale of the hydrodynamics, as seen in figure 7 .

The rate of bed growth of the other morphodynamic feature, the offshore bar, is significantly smaller: $\overline{\nabla d \boldsymbol{u}} \approx 0$ everywhere except over the offshore-travelling bar, where phase-averaged flow is slightly divergent, and in the region of infiltration for the permeable beach, where the flow is strongly convergent (see above).

In terms of duration the backwash is dominant in the lower swash (figure 8), with uprush and backwash becoming equal on approaching the limit of uprush, consistent with the Shen \& Meyer (1963) solution. Infiltration alters the balances in the upper swash in favour of uprush (figure 8). If we now examine the bed growth/decay terms in (4.1) (excluding diffusion and infiltration) we can see their effect on both phases of the swash (figure 9). On the uprush the concentration gradient is dominant in the lower swash, but flow convergence dominant in the upper swash. Thus if backwash were removed, there would be strong erosion in the lower swash and deposition in the upper swash.

\subsection{Two-dimensional hydrodynamics}

Turning now to the formation of the cusps themselves we first consider a non-erodible, impermeable bed, for $f_{w}=0$. In figure 10 we can see the resulting phase-averaged and alongshore-filtered flow

$$
\frac{1}{T} \int_{0}^{T}\left(u-\frac{1}{L_{y}} \int_{0}^{L_{y}} u \mathrm{~d} y, v\right) \mathrm{d} t .
$$

This flow exhibits alongshore spatial periodicity of about $5 \mathrm{~m}$, which increases to $\sim 7.5 \mathrm{~m}$, and finally breaks down into a disorganized flow. The addition of friction 

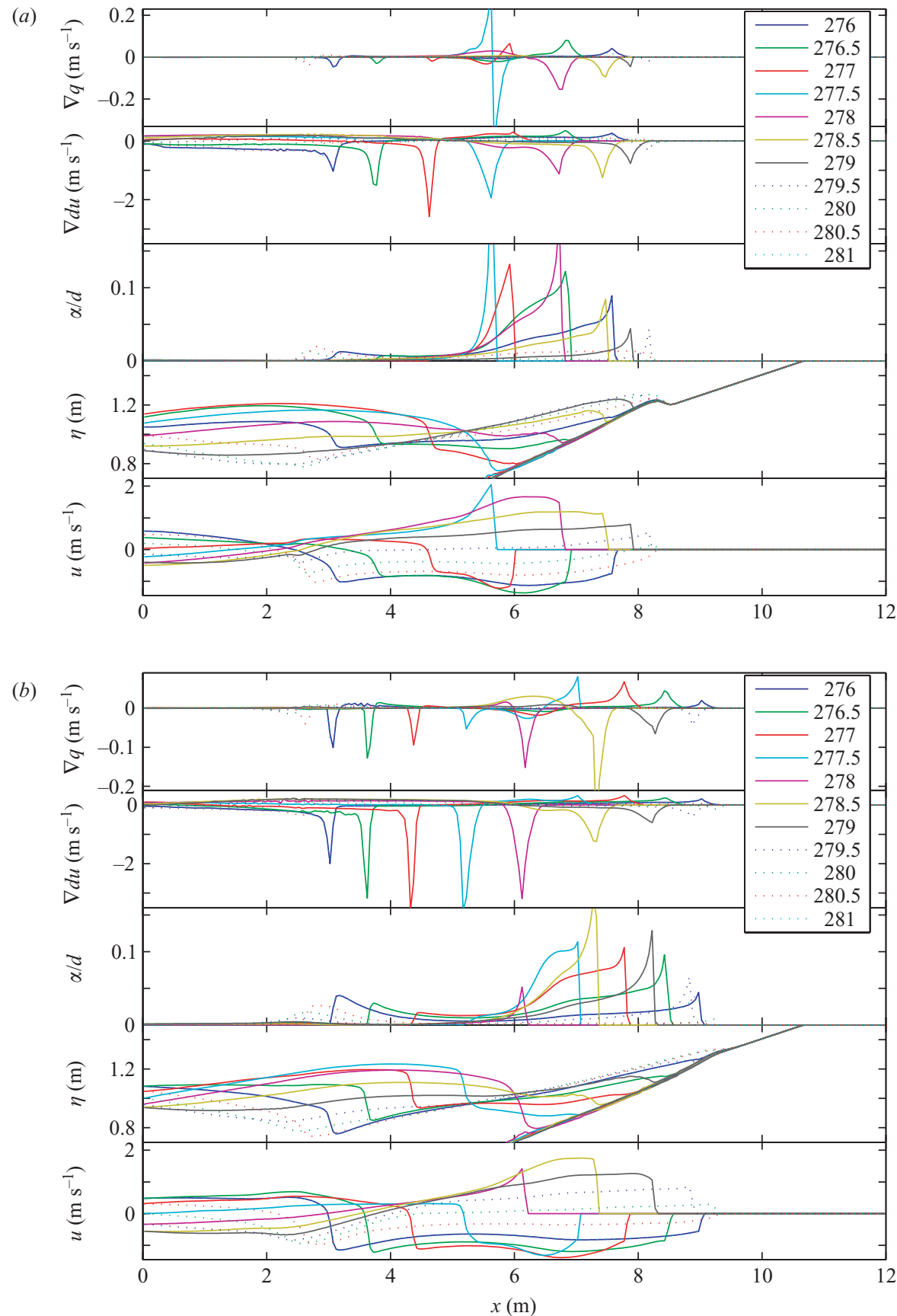

FIGURE 7. Cross-shore velocity, depth-averaged concentration, flow and sediment divergence for $(a)$ permeable beach and $(b)$ impermeable beach, cross-shore experiment from 276-281 s.

$\left(f_{w}=0.005\right)$ reduces the energy of the flow, stabilizes it, and preserves the shorter wavelength. Larger values of $f_{w}(>0.01)$ suppress the periodicity completely.

Other periods also exhibit alongshore-periodic averaged flows: these are shown in table 2 . The observed $\lambda_{\text {flow }}$ up to $T=6 \mathrm{~s}$ is, at least initially, close to that of linear, 

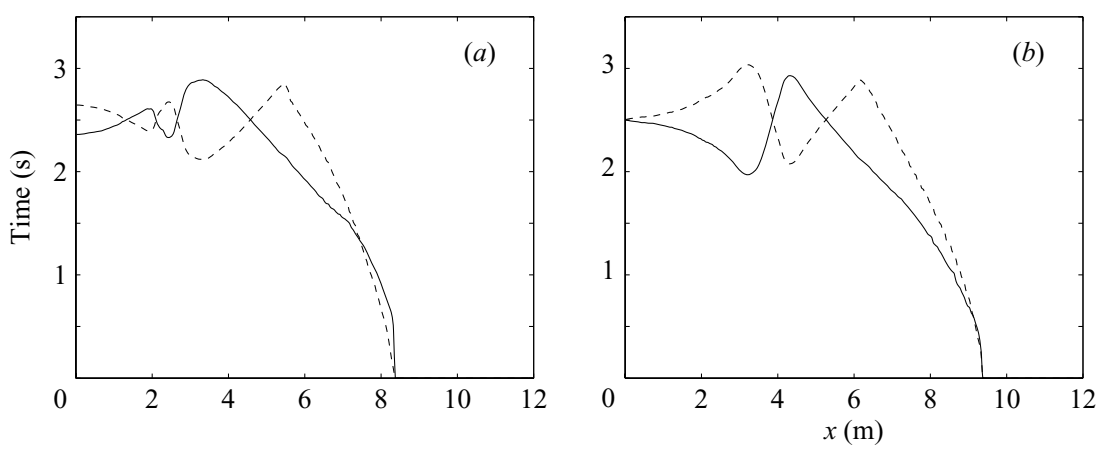

Figure 8. Time at each cross-shore location during which uprush $(u>0$, solid line) and backwash $(u<0$, dashed line) exists for $(a)$ permeable beach, and $(b)$ impermeable beach, during 276-281 s for cross-shore experiment.
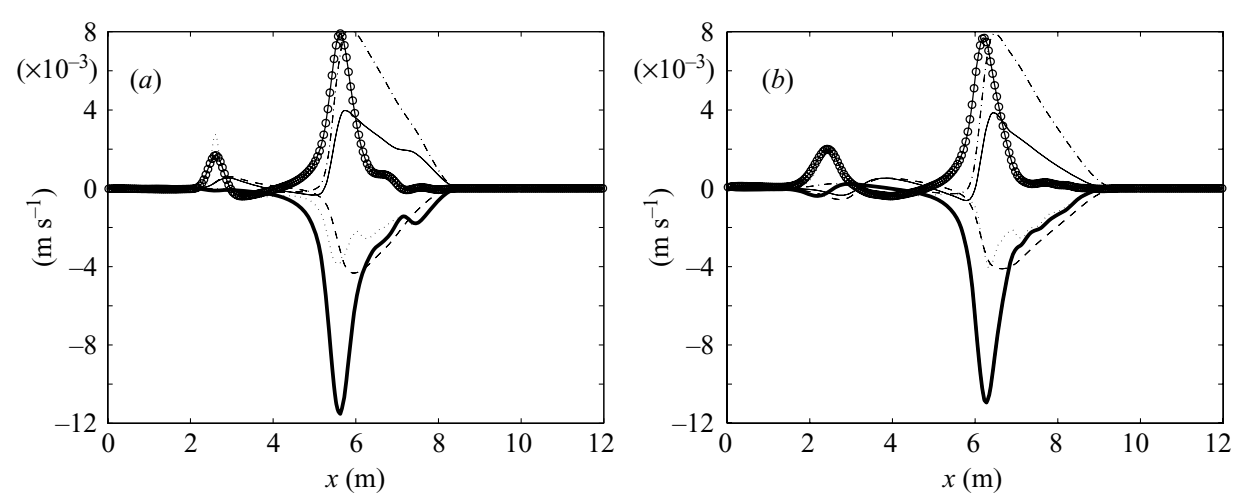

FIGURE 9. Phase-averaged flow divergence and concentration gradient terms in (4.1) for $(a)$ permeable beach and $(b)$ impermeable beach (cross-shore experiment from 276-281 s). Solid line: $\xi \overline{(\alpha / d) \eta_{, t}}$, total; dot-dash line: $\xi \overline{(\alpha / d) \eta_{, t}}$, uprush only; dashed line: $\xi \overline{(\alpha / d) \eta_{, t}}$, backwash only; dotted line: $-\xi \overline{d \boldsymbol{u} \cdot \nabla(\alpha / d)}$, total; thick solid line: $-\xi \overline{d \boldsymbol{d} \cdot \nabla(\alpha / d)}$, uprush only; line with circles: $-\xi \overline{d \boldsymbol{u} \cdot \nabla(\alpha / d)}$, backwash only.

synchronous (shallow water) edge waves on the same constant slope. For higher periods this correspondence disappears; at these periods there is significant reflection. The growth and equilibration of these flows is shown in figure 11, where the kinetic energies have been normalized by $S_{e}$.

The physical mechanism by which this hydrodynamic instability develops is related to the bore collapse event. For $T \leqslant 6 \mathrm{~s}$, the bore collapse itself drives the swash flow. So, if one region of an incoming wave front is of higher amplitude locally it will reach the shoreline (say at a point $y_{A}$ ) and run up the beach face slightly ahead of adjacent sections of the front. The resulting lateral pressure gradient then drives a flow to either side, which will both reduce subsequent backwash at $y_{A}$, and enhance that at either side $\left(y_{A} \pm \lambda_{\text {flow }} / 2\right)$. As long as the next wave encounters that enhanced backwash this will, in turn, further retard the subsequent uprush at these locations. A positive feedback mechanism is thus established, as long as the natural swash period $\left(T_{\text {swash }}\right)$ for that bore collapse event (see Baldock \& Holmes 1999) is close enough to the wave period $(T)$, i.e. if there is resonance between $T$ and $T_{\text {swash }}$ : see figure 11 . For a frictionless periodic shallow-water equation system where the swash is bore 

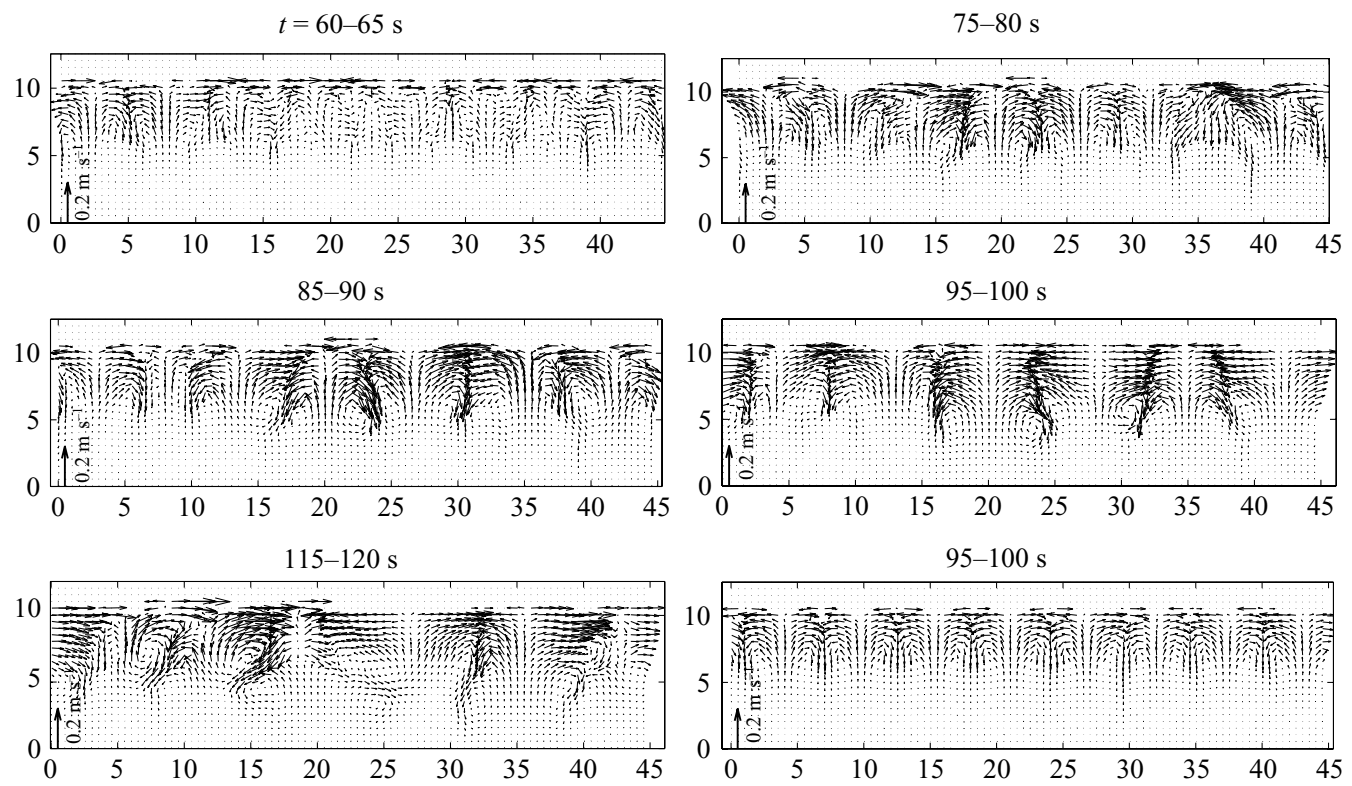

FIGURE 10. Phase-averaged and alongshore filtered flow field for a normally incident wave $\left(T=5 \mathrm{~s}, H_{0}=0.25 \mathrm{~m}\right)$ on a 0.14 impermeable, non-erodible slope for $f_{w}=0$, except for bottom right, where $f_{w}=0.005$.

\begin{tabular}{|c|c|c|c|c|c|c|c|c|c|}
\hline \multirow{2}{*}{$\begin{array}{l}T \\
{[\mathrm{~s}]}\end{array}$} & \multirow{2}{*}{$\begin{array}{c}d_{B} \\
{[\mathrm{~m}]}\end{array}$} & \multirow{2}{*}{$\begin{array}{c}u_{B} \\
{\left[\mathrm{~m} \mathrm{~s}^{-1}\right]}\end{array}$} & \multirow{2}{*}{$\begin{array}{c}S_{e} \\
{[\mathrm{~m}]}\end{array}$} & \multirow{2}{*}{\multicolumn{2}{|c|}{$\begin{array}{cc} & T_{\text {swash }} \\
|R| & {[s]}\end{array}$}} & \multirow{2}{*}{$\begin{array}{l}\lambda_{\text {flow }} \\
{[\mathrm{m}]}\end{array}$} & \multicolumn{2}{|c|}{$\lambda_{\text {syn }}$} & \multirow{2}{*}{$\begin{array}{c}\lambda_{\text {sub }} \\
(n=0)[\mathrm{m}]\end{array}$} \\
\hline & & & & & & & $(n=0)[\mathrm{m}]$ & $(n=1)[\mathrm{m}]$ & \\
\hline 3 & 0.12 & 0.63 & 1.55 & 0.08 & 3.48 & 2.6 & 1.97 & 5.90 & 7.87 \\
\hline 4 & 0.20 & 0.70 & 2.75 & 0.17 & 4.50 & $3.5 \rightarrow ?$ & 3.50 & 10.5 & 14.0 \\
\hline 5 & 0.28 & 0.72 & 4.05 & 0.01 & 5.28 & $5.1 \rightarrow 8.5(\sim 7.5) \rightarrow ?$ & 5.46 & 16.4 & 21.9 \\
\hline 6 & 0.38 & 0.52 & 5.45 & 0.39 & 5.79 & $4.3 \& 8.5 \rightarrow 8.5(\sim 10)$ & 7.87 & 23.6 & 31.5 \\
\hline 7 & 0.45 & 0.35 & 6.45 & 0.64 & 6.04 & 6.4 & 10.71 & 32.1 & 42.8 \\
\hline 8 & 0.49 & 0.1 & 7.25 & 0.76 & 5.94 & 8.5 & 13.99 & 42.0 & 56.0 \\
\hline
\end{tabular}

TABLE 2. Spacings of observed circulation patterns in hydrodynamic numerical experiments. One-dimensional: $d_{B}, u_{B}$ (depth and velocity at bore collapse), $S_{e},|R|$ (reflection coefficent, calculated from linear theory), and $T_{\text {swash }}$ (swash period, calculated according to ballistic theory using $R^{+}=u_{B}+2 \sqrt{g d_{B}}$ ). Two-dimensional: $\lambda_{\text {flow }}$ is the spatial period of phase-averaged flow field (if extant). If a pattern was visible a Fourier analysis was performed (at several points in the cross-shore variable $(x)$ ), and the position of the peak of the power density spectrum in wavenumber space used to define $\lambda_{\text {flow }}$. NB Because of limited alongshore domain length the spectral resolution at large wavelengths is limited. This only significantly affects the 5 and $6 \mathrm{~s}$ experiments, where the spectral estimate is different from the observed spacing (given in parentheses). Note also that for $6 \mathrm{~s}$ a smaller wavelength flow pattern was initially visible very close to the shore, and a larger one elsewhere. A subsequent breakdown in alongshore periodicity is indicated by a question mark. $\lambda_{\text {syn,sub }}$ are wavelengths of linear (shallow water, synchronous or subharmonic) edge waves. Simulations were run for 20-30 periods.

driven, a resonance (equlibrium) will always be established. The apparent detuning for small periods is possibly due to the increasing innacuracy of the correction based on the Shen \& Meyer solution and difficulties in obtaining precise velocities at collapse. For larger values of $|R|$ the bore collapse occurs with small $u_{B}$, as in the 

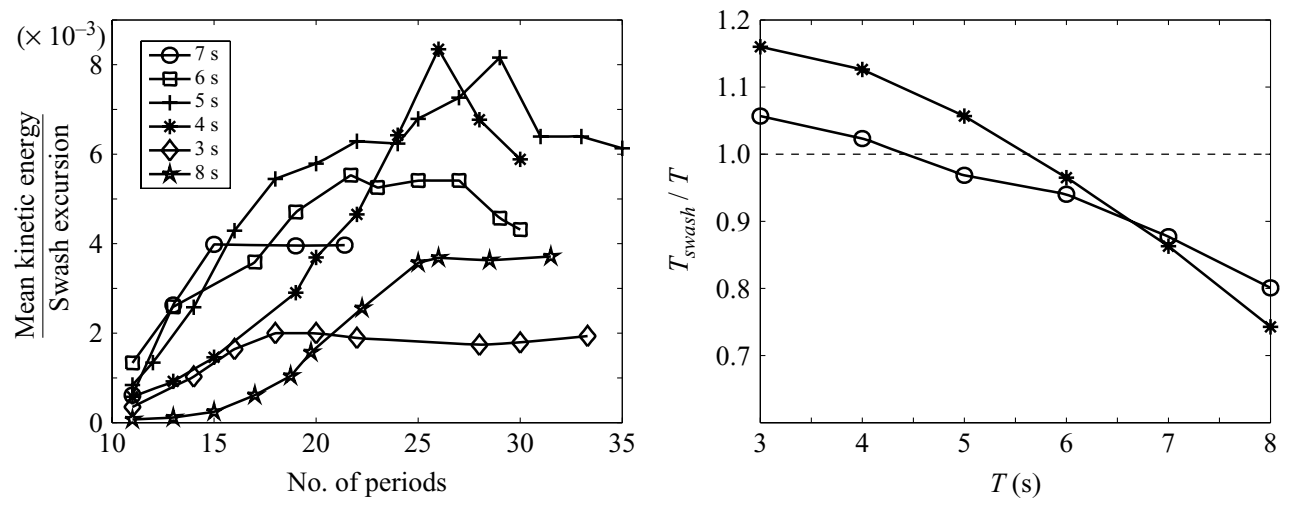

FigURE 11. (a) Normalized kinetic energy of phase- and alongshore-averaged flow as a function of time for the cases shown in table 2. (b) Swash period (normalized by wave period) calculated from ballistic theory both with $(*)$ and without $(\circ)$ correction for velocity at bore collapse $\left(u_{B}\right)$ and finite model minimum depth $\left(d_{\min }=2 \mathrm{~mm}\right)$. The 'corrected' swash period using the Shen \& Meyer (1963) solution is $T_{\text {swash }}=(4 / \sin \beta) \sqrt{\left(d_{b} / g\right)}-6 \sqrt{d_{\min } /(g \tan \beta \sin \beta)}$.

classical dambreak problem (see Shen \& Meyer 1963; Peregrine \& Williams 2001), but thereafter $R^{+}=u+2 \sqrt{g d}$ increases, making the subsequent swash event significantly different (i.e. non-bore-driven), because the wave is substantially reflected. Further, the feedback mechanism will be weaker for waves that propagate at the linear phase speed.

\subsection{Alongshore spacings}

This feedback mechanism feeds energy (initially at least) into synchronous edgewave-like modes. In figure 12 the instantaneous alongshore-filtered flow is shown through the wave cycle for $T=5 \mathrm{~s}\left(f_{w}=0.005\right)$; see also figure 10 for the phaseaveraged flow. Flow at adjacent nodes is very different, as might be expected if they are 'horn' and 'embayment' respectively. At $95.8 \mathrm{~s}$ a near maximum (if filtered flow velocities are used as an indicator of maximum standing wave amplitude) is achieved at alternate anti-nodes, approximately at maximum runup. Thereafter, flow reverses on the backwash (97.4 s) until the incoming wave front, being retarded by the excess backwash (98.6s) at alternate anti-nodes ('embayments'), is channelled initially into every other anti-node ('horns'). Thereafter ( $100 \mathrm{~s}$ ) flow reverses and the process begins again. The circulation cells behind the shoreline retain the same sense of rotation through the cycle. They are similar to those observed when a non-breaking standing wave is imposed on a synchronous edge wave (see Kaneko 1983). These features give a strong indication that a synchronous edge wave is excited by the swash resonance. Why the circulation associated with the 7 and $8 \mathrm{~s}$ waves (see figure 10) develops and has the observed wavelengths is not clear.

\subsection{Physical explanation for cusp formation}

These hydrodynamics raise questions regarding the swash morphodynamics, to which we now turn. The observed $\lambda_{c}$ for $T=5 \mathrm{~s}(8.3 \mathrm{~m})$ is larger than the equivalent initial $\lambda_{\text {fow }}$, although closer to $\lambda_{\text {flow }}$ for the circulation that subsequently develops: see figure 10. Figure 13 shows that cusp development happens after the cross-shore profile has already been progressing. Accordingly, figure 14 shows the calculated edge wave for the (non-erodible) bed profile illustrated, which is based on an alongshore-averaged profile of that shown in figure 2 after 40 periods with offshore portion following an 

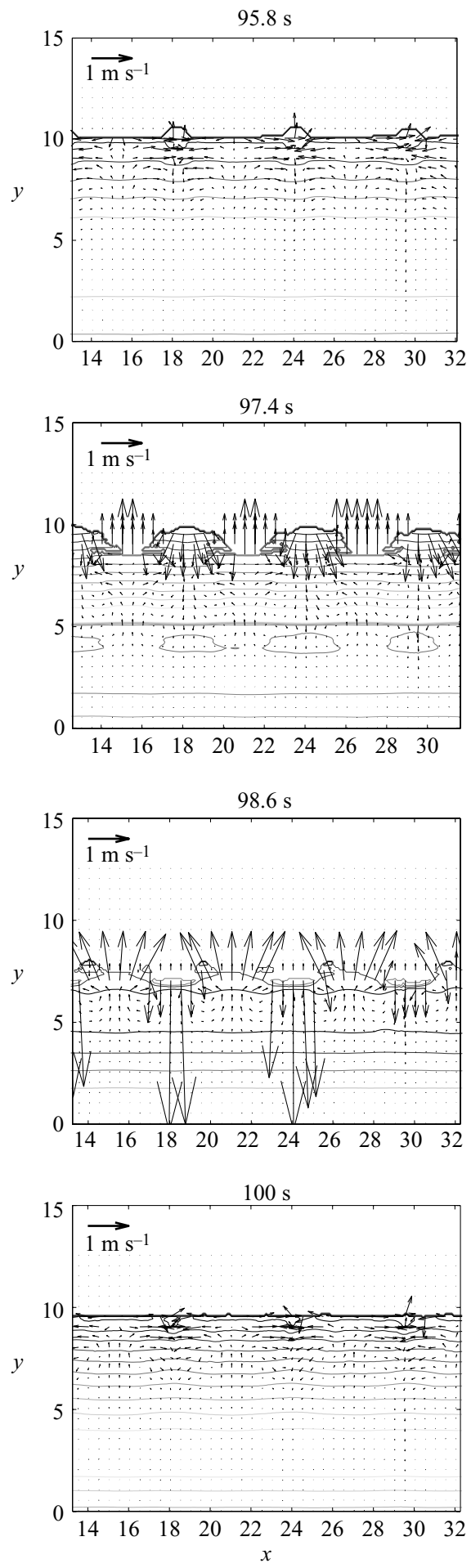

FiguRE 12. Alongshore filtered flow vectors and free surface elevation for $5 \mathrm{~s}$ wave $\left(f_{w}=0.005\right)$ after 24 periods. 


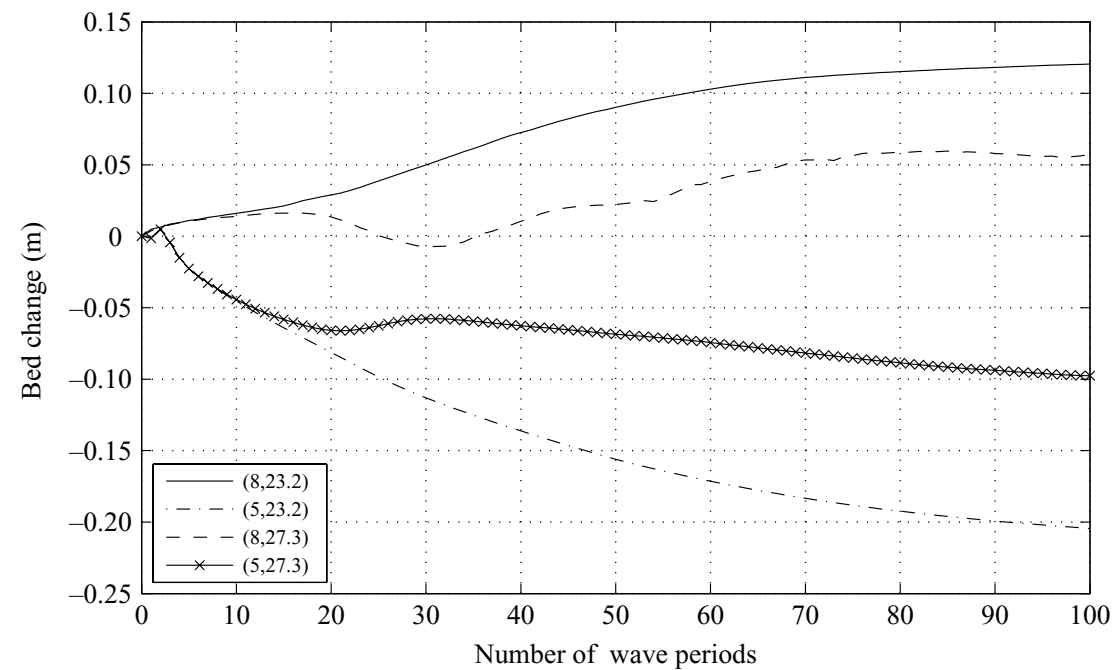

FIGURE 13. The time evolution of four key locations in the domain of figure 2.
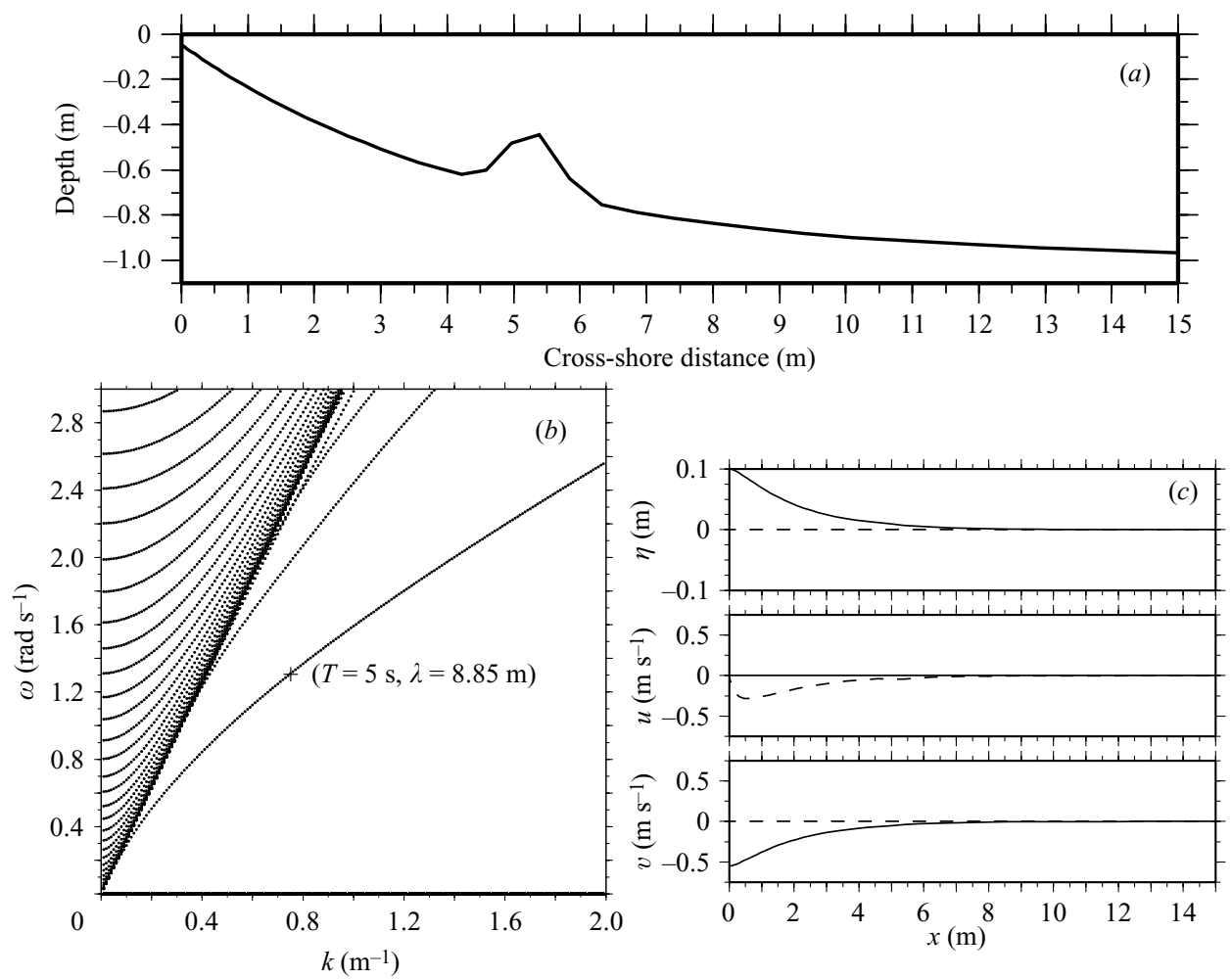

FIGURE 14. (a) Beach profile created from alongshore average of beach profile in figure 2 after 40 periods. (b) Dispersion curves for this beach. $T=5 \mathrm{~s}$ corresponds to $\omega=1.26 \mathrm{~m} \mathrm{~s}^{-1}$. (c) Linear $\eta, u$ and $v$ for $T=5 \mathrm{~s}(n=0)$ edge wave. Solid (broken) lines are real (imaginary) parts.

exponential decay to a constant offshore value. The slope at the shoreline is about 0.2. The resulting dispersion diagram reveals a (mode 0 ) edge wave with $\lambda_{\text {syn }}=8.9 \mathrm{~m}$, which is limited primarily to the region shoreward of the bar. 
We can now understand this cusp formation mechanism. In figure 15 we see the cusp formation mechanism for an embayment and horn over one cycle. At $245 \mathrm{~s}$ we see the beginning of rundown and flow divergence at a horn. By $246.2 \mathrm{~s}$ the backwash has eroded some of the horn. Note the shoreward movement in bed contours as the wave front passes, particularly those below the zero level. As the front passes the divergence effect removes sediment as a bed wave propagates offshore. The concentration gradient mostly acts now to accrete $(-\xi d \boldsymbol{u} \cdot \nabla C>0)$ : see the bottom right of the figure, where the front has yet to pass. Note how far behind the horn backwash is that in the embayment. At $248 \mathrm{~s}$ the uprush is strong and clearly occurs first at the horn centre, and thereafter (248.6 s) splits to each side of the horn. There is a very high concentration at the wave front, and a clear depositional effect associated with its passage. The wave front is retarded on the horn, leading to $d v C_{, y}<0$ each side of the horn, thus diminishing the erosional effect of this term. Again, note that on the uprush the embayment flow initially lags behind that at the horns. At $249.6 \mathrm{~s}$ the flow has begun to recede in the lower swash, and in the upper swash it splits to each side of the horn; much of this flow returns via the embayment and not down the horn. The horn (positive perturbation) therefore reduces backwash (and also through infiltration). At the end of the cycle there is deposition (erosion) at the horn location everywhere above (below) the zero contour.

The erodible bed enhances the swash resonance effect, because a larger wave (at $y_{A}$ recall) will not only produce the hydrodynamic effects (lateral pressure gradients inducing a splitting of the uprush and thereafter interaction with the backwash) but also enhanced deposition at $y_{A}$ and erosion at $y_{A} \pm \lambda_{c} / 2$ in the upper swash, consistent with cusp horns and embayments. This explains why cusps develop for $T=7 \mathrm{~s}$ for $\lambda_{c}>\lambda_{\text {flow }}$ of table 2 , and why $f_{w}=0.05$ does not damp out circulation (as it does for the hydrodynamic experiments). Infiltration also enhances cusp formation by reducing further backwash at incipient cusp locations. Two processes limit the size of cusps: bed downslope sediment transport, and the gradually increasing value of $|R|$, which counteracts the swash resonance. A morphodynamical simulation run with the equilibrium profile of figure 4 extended alongshore (for which $|R|=0.31$ after 5 periods, 0.53 after 80 periods, and 0.75 at equilibrium), shows no cusp development after 100 periods.

\section{Concluding remarks}

The morphodynamical simulations indicate increasing (linear) cusp growth rates for decreasing periods (impermeable), and a growth rate peak at about a $4 \mathrm{~s}$ period (permeable). For smaller periods (i.e. smaller Irribarren number) the waves in reality become spilling, so the dynamics of the swash will change from those illustrated, to those for real random seas, in which the low-frequency signal (even for a narrowbanded sea) will swamp individual shoreline wave motions. Therefore this trend should be viewed as applying only until the nature of the breaking changes.

The result is that there is likely to be a most favourable wave period at which a beach will exhibit cusp development, at least by bore-driven mechanisms.

The (hydrodynamical) result that a fully reflective wave does not generate 'cusp-like' circulation (borne out also by the decreasing growth rate for the morphodynamical simulations) is at first surprising, because cusps are generally associated with reflective beaches. However, the increased instability of the morphodynamical system (compared to the hydrodynamical one) should be noted, i.e. highly reflective beaches, e.g. for $T=7 \mathrm{~s}$, produce cusp spacings that have no hydrodynamical equivalent. Further, 

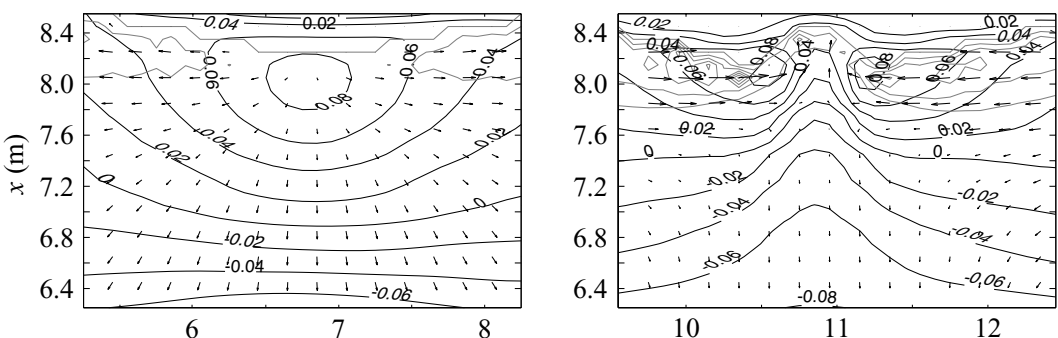

(a)
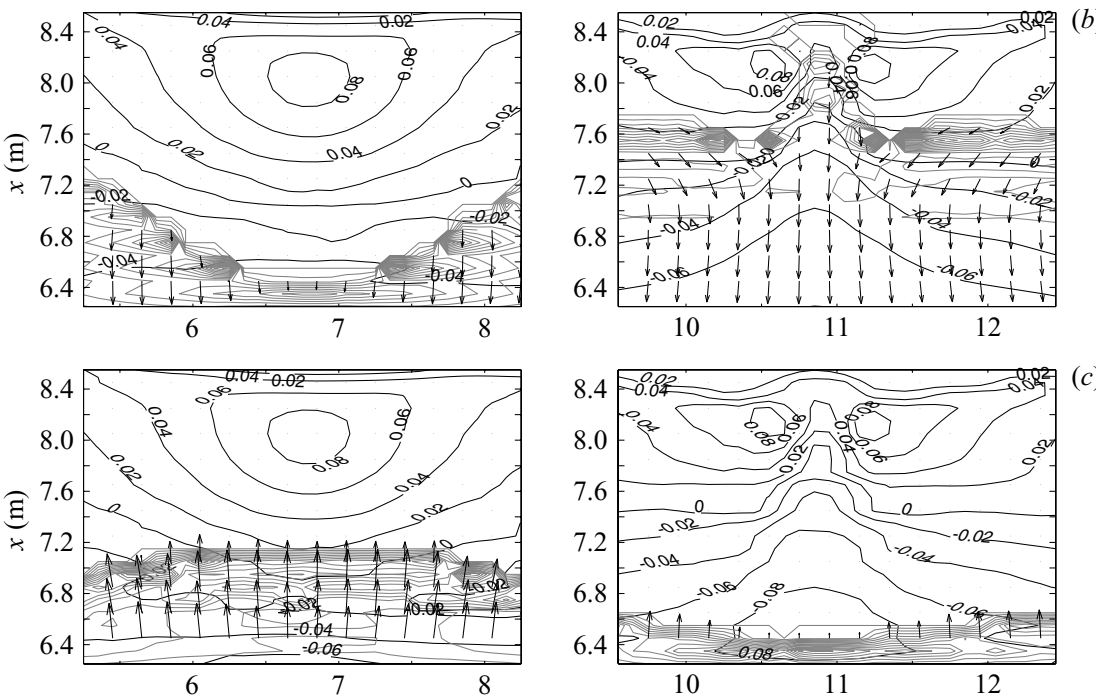

(c)
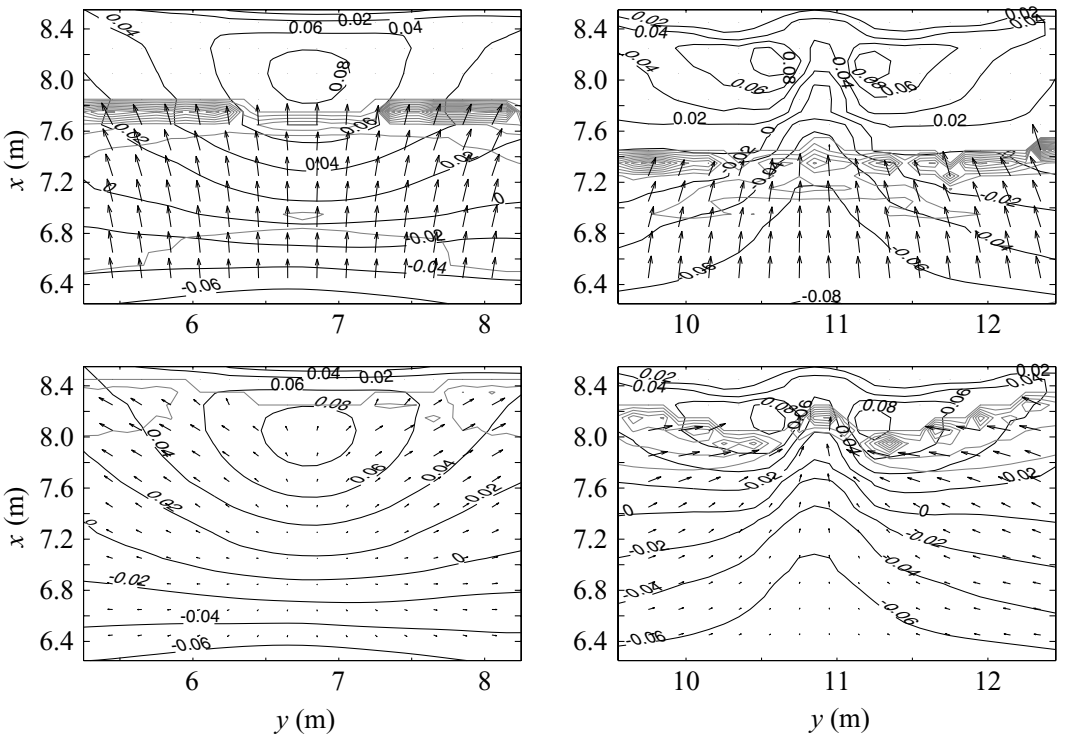

FigURE 15. Bed perturbations (black labelled contours), concentration (grey contours) and velocity vectors over a wave cycle at a cusp horn $(a)$ and an embayment $(b)$ in a permeable beach experiment (see figure 2) during 245-250 s. (a) $t=245 \mathrm{~s},(b) t=246.2 \mathrm{~s},(c) t=248 \mathrm{~s}$, (d) $t=248.6 \mathrm{~s},(e) t=249.6 \mathrm{~s}$ 
fully reflective waves are known to excite subharmonic standing edge waves (Guza \& Inman 1975). The alongshore domain length here precluded this process (because $n \lambda_{\text {sub }} \neq L_{y}$ for small $n$ ). Note also that the swash beach profile is reworked by the waves so as to become more reflective (both in one and two dimensions). Thus, beaches that are initially only mildly reflective may become highly reflective during the process of cusp development, which may obscure the 'initial' beach conditions and result in field observations that incorrectly assess the beach reflectivity associated with cusp development.

Observed cusp spacings $\left(\lambda_{c}\right)$ are from the middle to the upper end of the range found by Coco et al. (2000) in their modelling. The growth rates calculated here are very high, but it should be noted that this is the linear growth rate (from very early in their development, where the evolution of the spectral peak is approximately exponential). Further, a smaller $A$ is likely to lead to smaller growth rates.

Beach permeability clearly favours cusp development, by enhancing the feedback mechanism (e.g. less backwash and therefore offshore sediment transport at horns). Other onshore swash sediment transport processes are also likely to be more auspicious for cusp development, due to the horns being built quicker (and therefore their initial feedback in diverting the flow into the embayments increased, thereby transporting more sediment offshore in increased backwash). Note, however, that this may also result in a gradual filling in of the embayments.

The notable phase lag between horn/embayment/uprush/backwash results in a strong jet-like flow from the embayment as the next wave approaches. This is frequently observed in the field.

A.M.S. was supported by the UK Engineering and Physical Sciences Research Council (EPSRC). Additional financial support was received from the University of Nottingham. D. C. was supported by funding from the Ministerio de Ciencia y Tecnologia of Spain for the 'Ramón y Cajal' contract. A. S. was supported by the Royal Thai Government and by the Department of Water Resources Engineering, Chulalongkorn University. The authors would like to express their gratitude to the late Professor D. H. Peregrine of the University of Bristol for very useful discussions and observations concerning this work.

\section{Appendix A. Infiltration}

Equation (2.6) is more usually referred to as the Green-Ampt approximation (see Chow et al. 1988). We ignore the suction head in (2.6), and (implicitly) in our internal water table estimates. For a 'sand' beach Chow et al. (1988) give $5 \mathrm{~cm}$ for the suction head, and for a coarse sand beach $\left(K \approx 1 \mathrm{~cm} \mathrm{~s}^{-1}\right)$ we may expect it to be less than this. This effect will reduce the distance between the descending front and the water table, and therefore infiltration too. We also ignore lateral diffusion, which will reduce $\zeta_{, t}$ as water penetrates further shoreward. These terms are thus opposing.

In $\S 2.1 .1$ we note that over the first time-step in the infiltration calculation we follow Packwood (1983) (and Karambas 2003) in assuming a linear variation in depth of water $(d)$, from 0 to $\mathscr{H}_{0}$, as a cell initially wets. This is done primarily to avoid the initial singularity in (2.6) when $\zeta=0$. Thus

$$
d\left(\boldsymbol{x}_{i j}, t\right)=\frac{\mathscr{H}_{0}}{\delta t}\left(t-t_{n}\right) \text { for } t_{n} \leqslant t \leqslant t_{n}+\delta t,
$$



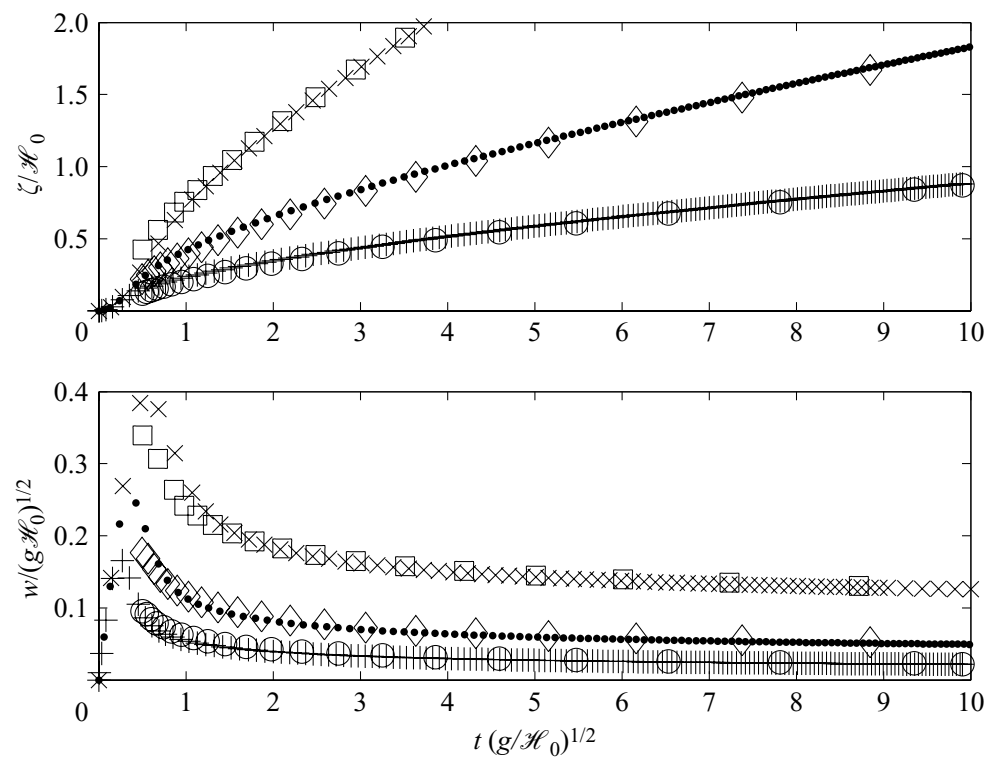

FIGURE 16. Non-dimensional $\zeta(a)$ and $w(b)$ calculated from inertialess equations (A 1) and (2.6) (for $\delta t=2 \sqrt{g / \mathscr{H}_{0}}$ and with $d=\mathscr{H}_{0}$ ), and from (A 2), which includes the initial acceleration. (A 1) and (2.6): $\mathscr{H}_{0}=0.1 \mathrm{~m}(\square) ; \mathscr{H}_{0}=0.01 \mathrm{~m}(\diamond) ; \mathscr{H}_{0}=0.001 \mathrm{~m}(\bigcirc)$. (A 2): $\mathscr{H}_{0}=0.1 \mathrm{~m}(\times) ; \mathscr{H}_{0}=0.01 \mathrm{~m}(\bullet) ; \mathscr{H}_{0}=0.001 \mathrm{~m}(+)$.

where $\delta t$ is the first time-step of the infiltration calculation. This is done using a particular solution of (2.6) for such a linear variation (Packwood 1983): $\dagger$

$$
\zeta=\frac{K}{2 n}\left[1+\left\{1+\frac{4 n \mathscr{H}_{0}}{K \delta t}\right\}\right]\left(t-t_{n}\right) .
$$

This approach has physical appeal because in reality any location will not wet discontinuously. However, the time scale of initial wetting is likely to be very small compared with that of infiltration, and, in the initial time step, inertial effects may be important. To examine the feasibility of using (A 1) we show in figure $16 \mathrm{w}$ and $\zeta$ as calculated from (A 1) and (2.6), and for (2.6) with an additional inertial head included:

$$
\mathscr{H}_{0}+\zeta=\frac{w}{K} \zeta+\frac{\mathscr{H}_{0}}{g} \frac{\mathrm{d} w}{\mathrm{~d} t}
$$

where $\mathscr{H}_{0}$ is a constant head. It can be seen that the approach, with $\delta t$ of the order of the inertial time scale $\left(\sqrt{\mathscr{H}_{0} / g}\right)$, works reasonably well in reproducing the peak $w$. Because the inertial behaviour is restricted to a small time at the beginning of infiltration the infiltrating volume in the two different approaches is not significantly different even at the first time-step.

$\dagger$ There appears to be a misprint in Packwood (1983) and Karambas (2003). Equation (6) of Packwood (1983) ((21) of Karambas (2003)) requires an extra factor of $1 / 2$ multiplying the right-hand side. 

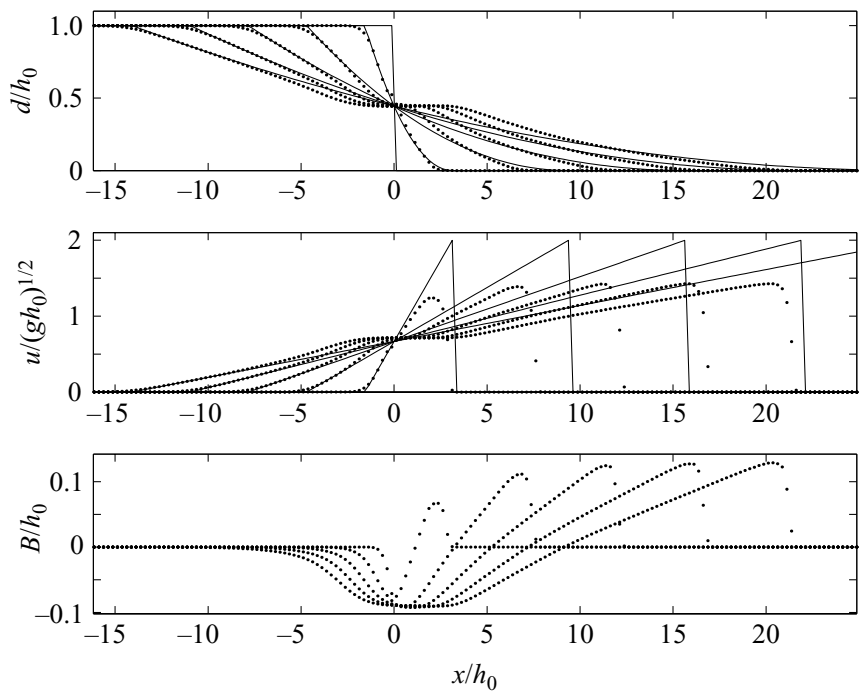

FiguRE 17. Water depth, velocity and bed level for a dambreak problem on a mobile, impermeable bed using the nonlinear shallow water equations, and (2.1) with (2.7). Initial conditions $(d(x<0,0)=1 \mathrm{~m}$, still water). Also shown (solid lines) is the analytical solution for the classical equivalent dambreak problem on an immobile bed.

\section{Appendix B. Dambreak problem}

In figure 17 we present the numerical solution for the dambreak problem defined by our equation system.

\section{Appendix C. Shen \& Meyer solution}

The solution of Shen \& Meyer (1963) (see also Peregrine \& Williams 2001) can be used to illustrate the different physical effects embodied in (4.1). Using the nondimensionalization of Peregrine \& Williams (2001) the Shen \& Meyer solution can be written

$$
\begin{aligned}
d(x, t) & =\frac{1}{36 t^{2}}\left(4 t-t^{2}-2 x\right)^{2}, \\
u(x, t) & =\frac{2}{3 t}\left(t-t^{2}+x\right), \\
x_{s}(x, t) & =2 t-\frac{1}{2} t^{2},
\end{aligned}
$$

where $x_{s}$ is the shoreline. If we ignore infiltration and bed diffusion, we can recover (4.1) assuming we replace the dimensional sediment transport constant $A$ by nondimensional $\hat{A}=A g \cos \beta$. We find

$$
\begin{aligned}
\eta_{, t} & =\frac{1}{36}\left(2 t-8+16 \frac{x}{t^{2}}-8 \frac{x^{2}}{t^{3}}\right), \\
C_{, x} & =96 \frac{t\left(t-t^{2}+x\right)(2-t)}{\left(4 t-t^{2}-2 x\right)^{3}} .
\end{aligned}
$$




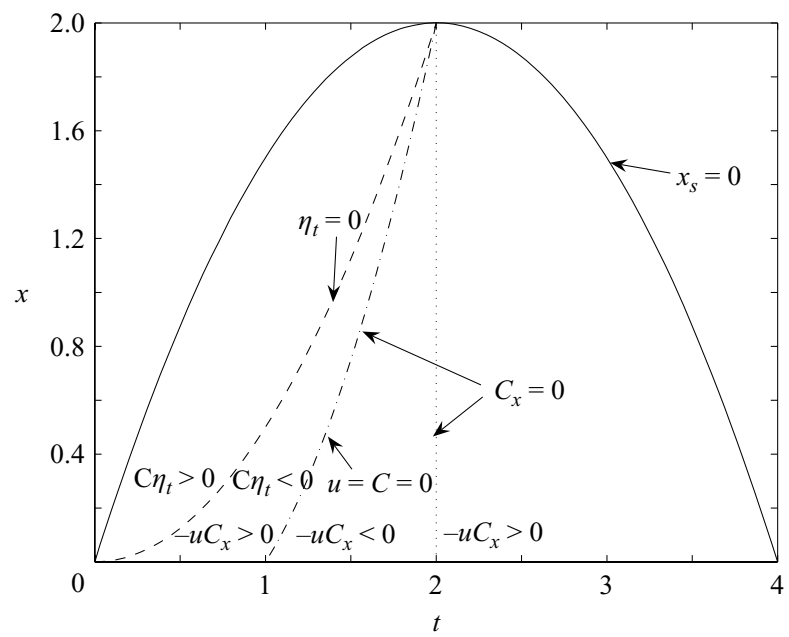

FIGURE 18. Illustration of regions in which flow divergence and concentration gradient terms change sign in the Shen \& Meyer solution.
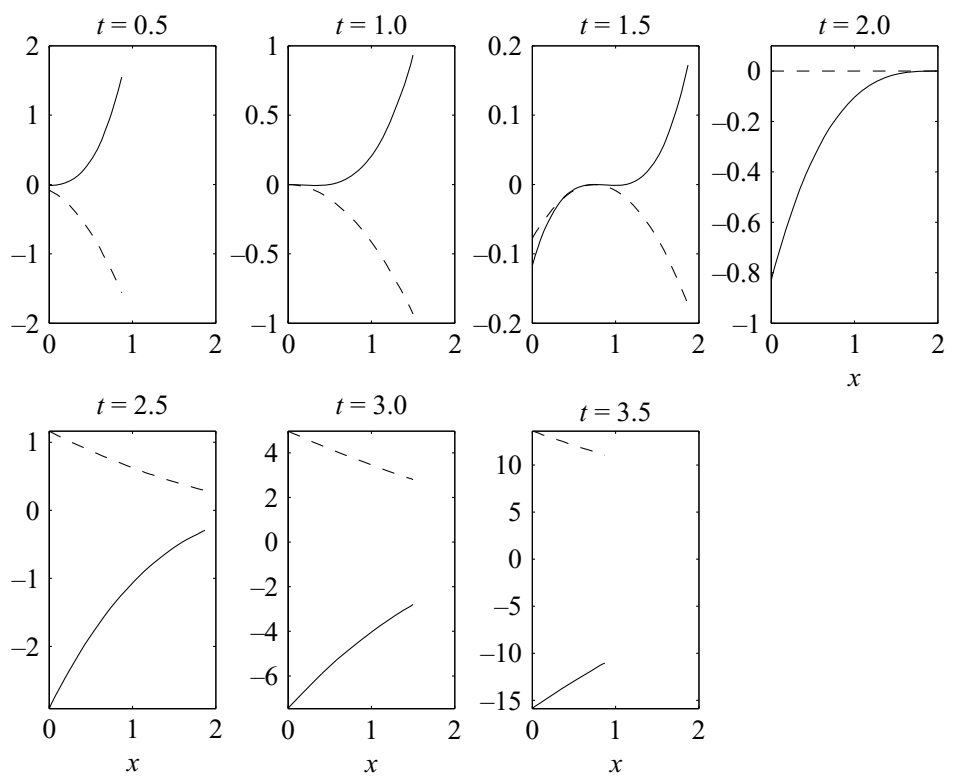

FIGURE 19. Non-dimensional concentration gradient and flow divergence terms for the Shen and Meyer solution at various times. Solid line: $C \eta_{, t}$; dashed line: $-d u C_{, x}$. Note that the different plots are not directly comparable because the factor $d^{1 / 2}$ has been factored out of both expressions to avoid the singularity at the shoreline.

In figure 18 the regions in which the main terms leading to erosion and accretion change sign are shown. In figure 19 we see the effect of the flow divergence and concentration gradient terms for the same solution. Note that because the bed is non-erodible for this solution $d_{, t}=\eta_{, t}$, so there is no factor $1+\xi C$ on the left of (4.1), which leads to singularities in both flow divergence and concentration gradient terms as $x \rightarrow x_{s}$, which vanishes upon addition of the two terms. 


\section{REFERENCES}

BALdock, T. E. \& Holmes, P. 1999 Simulation and prediction of swash oscillations on a steep beach. Coastal Engng 36, 219-242.

Butt, T., Russell, P., Puleo, J., Miles, J. \& Masselink, G. 2004 The influence of bore turbulence on sediment transport in swash and inner surf zones. Continent. Shelf Res. 24, $757-771$.

Calvete, D., Dodd, N., Falques, A. \& Van Leeuwen, S. M. 2005 Morphological development of rip channel systems: normal and near normal wave incidence. J. Geophys. Res. 110 (C10), C10007, doi:10.1029/2004JC002803.

Chow, V. T., Maidment, D. R. \& Mays, L. W. 1988 Applied Hydrology. McGraw-Hill.

Ciriano, Y., Coco, G., Bryan, K. \& Elgar, S. 2005 Field observations of swash zone infrgravity motions and beach cusp evolution. J. Geophys. Res. 110(C02018), doi:10.1029/2004JC002485.

Coco, G., Burnet, T. K., Werner, B. T. \& Elgar, S. 2003 Test of self-organization in beach cusp formation. J. Geophys. Res. 108(C3) (3101), doi:10.1029/2002JC001492.

Coco, G., Huntley, D. A. \& O'Hare, T. J. 2000 Investigation into a self-organization model for beach cusp formation. J. Geophys. Res. 105(C9), 21991-22002.

Coco, G., O'Hare, T. J. \& Huntley, D. A. 1999 Beach cusps: A comparison of data and theories for their formation. J. Coastal Res. 15, 741-749.

Dicker, D. 1969 Transient free surface flow in porous media. In Flow through Porous Media (ed. R. J. M. DeWiest), pp. 293-330. Academic.

DYer, K. R. 1986 Estuarine and Coastal Sediment Dynamics. Wiley.

FAlqués, A., Coco, G. \& Huntley, D. A. 2000 A mechanism for the generation of wave driven rhythmic patterns in the surf zone. J. Geophys. Res. 105 (C10), 24071-24087.

GuzA, R. T. \& Bowen, A. J. 1981 On the amplitude of beach cusps. J. Geophys. Res. 86, 41254132.

Guza, R. T. \& Inman, D. L. 1975 Edge waves and beach cusps. J Geophys. Res 80, 2997-3012.

Hsu, T. \& Raubenheimer, B. 2006 A numerical and field study on inner-surf and swash sediment transport. Continent. Shelf Res. 26, 589-598.

HubBard, M. E. \& DodD, N. 2002 A 2-d numerical model of wave run-up and overtopping. Coastal Engng 47(1), 1-26.

Hudson, J., Damganrd, J. S., Dodd, N., Cooper, A. J. \& Chesher, T. J. 2005 Approaches to 1d morphodynamical modelling in coastal engineering. Coastal Engng 52(8), 691707.

Hudson, J. \& Sweby, P. K. 2003 Formulations for numerically approximating hyperbolic systems governing sediment transport. J. Sci. Comp. 19, 225-252.

Inman, D. L. \& GuZA, R. T. 1982 The origin of swash cusps on beaches. Mar. Geol. 49, 133148.

KANEKo, A. 1983 A numerical experiment on nearshore circulation in standing edge waves. Coastal Engng 7, 271-284.

Karambas, T. V. 2003 Modelling of infiltration-exfiltration effects of cross-shore sediment transport in the swash zone. Coastal Engng J. 45(1), 63-82.

Komar, P. D. \& Holman, R. A. 1986 Coastal processes and the development of shoreline erosion. Annu. Rev. Earth Planet. Sci. 14, 237-265.

Masselink, G. \& LI, L. 2001 The role of swash infiltration in determining the beachface gradient: a numerical study. Mar. Geol. 176, 139-156.

Masselink, G. \& Pattiaratchi, C. B. 1998 Morphological evolution of beach cusps and associated swash circulation. Mar. Geol. 146, 93-113.

Masselink, G., Russell, P., Coco, G. \& Huntley, D. 2004 Test of edge wave forcing during formation of rhythmic beach morphology. J. Geophys. Res. 109 (C06003), doi:10.1029/2004JC002339.

MeI, C. C. 1990 The Applied Dynamics of Ocean Surface Waves, 2nd edn. World Scientific.

PACKwood, A. R. 1983 The influence of beach porosity on wave uprush and backwash. Coastal Engng 7(1), 29-40.

Packwood, A. R. \& Peregrine, D. H. 1980 The propagation of solitary waves and bores over a porous bed. Coastal Engng 3, 221-242. 
Peregrine, D. H. \& Williams, S. M. 2001 Swash overtopping a truncated beach. J. Fluid Mech. 440, 391-399.

Pritchard, D. \& HogG, A. J. 2005 On the transport of suspended sediment by a swash event on a plane beach. Coastal Engng 52, 1-23.

SAllenger, A. 1979 Beach-cusp formation. Mar. Geol. 29, 23-37.

Shen, M. C. \& Meyer, R. E. 1963 Climb of a bore on a beach. Part 2. Non-uniform beach slope. J. Fluid Mech. 16, 108-112.

Werner, B. T. \& Fink, T. M. 1993 Beach cusps as self-organized patterns. Science 260, 968-971. 